\title{
Water Mass Conversion, Fluxes, and Mixing in the Scotia Sea Diagnosed by an Inverse Model
}

\author{
Alberto C. Naveira Garabato \\ School of Environmental Sciences, University of East Anglia, Norwich, United Kingdom \\ DAVID P. STEVENS \\ School of Mathematics, University of East Anglia, Norwich, United Kingdom \\ KAREN J. HEYWOOD \\ School of Environmental Sciences, University of East Anglia, Norwich, United Kingdom
}

(Manuscript received 20 August 2002, in final form 28 May 2003)

\begin{abstract}
An inverse box model of the Scotia Sea is constructed using hydrographic, tracer, and velocity data collected along the rim of the basin during the Antarctic Large-Scale Box Analysis and the Role of the Scotia Sea (ALBATROSS) cruise. The model provides an estimate of the time-mean three-dimensional circulation as the Antarctic Circumpolar Current (ACC) crosses the region. It concurrently solves for geostrophic and wind-driven Ekman transports across the boundaries of the basin, air-sea-driven diapycnal fluxes, and "interior" diapycnal fluxes below the ocean surface. An increase is diagnosed in the ACC volume transport from $143 \pm 13 \mathrm{~Sv}$ ( $\mathrm{Sv}$ $\equiv 10^{6} \mathrm{~m}^{3} \mathrm{~s}^{-1}$ ) at Drake Passage to $149 \pm 16 \mathrm{~Sv}$ on leaving the Scotia Sea, supplied by the import of $5.9 \pm$ 1.7 Sv of Weddell Sea Deep Water (WSDW) over the South Scotia Ridge. There is a lateral redistribution of the transport, primarily in response to a topographically induced branching of the 70-80 Sv polar front (PF) jet and an increase in the transport associated with the subantarctic front (SAF) from $31 \pm 7$ to $48 \pm 4 \mathrm{~Sv}$. A vertical rearrangement of the transport also occurs, with differences $O(2 \mathrm{~Sv})$ in the transports of intermediate and deep water masses. These volume transport changes are accompanied by a net reduction (increase) in the heat (freshwater) flux associated with the ACC by $0.02 \pm 0.020 \mathrm{PW}(0.020 \pm 0.017 \mathrm{~Sv})$, the main cause of which is the cooling and freshening of the Circumpolar Deep Water (CDW) layer in the Scotia Sea. The model suggests that the Scotia Sea hosts intense diapycnal mixing in the ocean interior extending 1500-2000 m above the rough topography of the basin. Despite these model results, no evidence is found for a significant diapycnal link between the upper and lower classes of CDW (and hence between the "shallow" and "deep" cells of the Southern Ocean meridional overturning circulation). On the contrary, the boundary between Upper and Lower CDW separates two distinct regimes of diapycnal mixing involving volume fluxes of 1-3 Sv. Whereas in the denser waters topographic mixing is important, in lighter layers air-sea-driven diapycnal volume fluxes are dominant and diapycnal transfers of heat and freshwater are mainly effected by upper-ocean mixing processes. The model indicates that the ventilation of the deep ACC in the Scotia Sea is driven primarily by isopycnal exchanges with the northern Weddell Sea and to a lesser extent by diapycnal mixing with WSDW. The model reveals the existence of a mesoscale eddy-driven overturning circulation across the ACC core involving an isopycnal poleward transport of $8 \pm 1 \mathrm{~Sv}$ of $\mathrm{CDW}$ and an equatorward transport of intermediate water of the same magnitude. This circulation induces a cross-ACC poleward heat flux of $0.022 \pm 0.009 \mathrm{PW}$ and an equatorward freshwater flux of $0.02 \pm 0.01 \mathrm{~Sv}$. Adequately scaled, the former compares favorably to measurements of the cross-stream eddy heat flux by moored current meters and floats in the ACC and to budget estimates of the circumpolar cross-ACC heat flux.
\end{abstract}

\section{Introduction}

The meridional overturning circulation of the global ocean is crucially dependent on physical oceanographic

Corresponding author address: Dr. Alberto C. Naveira Garabato, School of Environmental Sciences, University of East Anglia, Norwich NR4 7TJ, United Kingdom.

E-mail: a.naveira-garabato@uea.ac.uk processes in the Southern Ocean. The absence of land barriers in the latitude band of Drake Passage permits the vigorous eastward flow of the Antarctic Circumpolar Current (ACC), which connects the three major ocean basins and couples their meridional transports of heat, freshwater, and other climatically important tracers. A global overturning thus exists in which North Atlantic Deep Water is exported to the Atlantic sector of the Southern Ocean, distributed circumpolarly by the ACC 
as Circumpolar Deep Water (CDW), and eventually returned toward the North Atlantic as intermediate and bottom water. Following the early work of Georgi and Toole (1982), a number of inverse box studies have sought to determine the meridional property fluxes associated with the southern limb of the overturning in each of the three major ocean basins by reference to property flux divergences between the ACC choke points (among others, Rintoul 1991; Macdonald 1998; Ganachaud and Wunsch 2000; Sloyan and Rintoul 2001). Convergence of net heat and freshwater flux estimates is now being achieved on these basin scales (Ganachaud and Wunsch 2003), but the sequence of regional water mass transformations along the ACC leading to the basin-scale overturning remains unresolved. Yet a quantitative knowledge of the circulation at these subbasin scales is critical to establishing the magnitude, pathways, and mechanisms of the Southern Ocean contribution to deep global ocean ventilation.

In present views of the Southern Ocean [e.g., Speer et al. (2000); see Rintoul et al. (2001) for a review], the extension of the zonally averaged meridional overturning circulation across the ACC is dominated by a "shallow" cell, in which a northward wind-driven Ekman transport is fed by a net southward transport of Upper CDW (UCDW) at greater depth followed by entrainment into the surface mixed layer in the southern ACC. The northward Ekman transport supplies the near-surface waters involved in the production near the northern edge of the ACC of Subantarctic Mode Water (SAMW) and Antarctic Intermediate Water (AAIW). These water masses are subsequently exported to the neighboring subtropical gyres. Beneath UCDW, Lower CDW (LCDW) is also transported southward across the ACC and beyond, toward the Antarctic margins, where it participates in the formation of Antarctic Bottom Water. This bottom water spreads northward across the deepest layers of the ACC and entrains gradually into the overlying LCDW, thereby forming a second "deep" overturning cell. In this paradigm, the southward transport of CDW is thought to occur primarily along isopycnals, with an important dynamical distinction between the lighter and denser fractions of the water mass: the southward transport of the denser layers can conceivably be supported by a net southward geostrophic flow below the sill of topographic features where a net pressure gradient can be established across Drake Passage latitudes; in contrast, a southward transport of the lighter CDW above that sill must be the manifestation of a rectified southward mass flux associated with the timevarying geostrophic flow of the mesoscale eddy field (Karsten et al. 2002; Bryden and Cunningham 2003).

Owing to the scarcity of quantitative observations, the role of diapycnal mixing processes in the Southern Ocean overturning is unclear. The involvement of airsea-driven diapycnal transfers in closing the upper limb of the shallow cell is recognized, but diapycnal mixing in the deep ocean is often presumed to be of little im- portance. The latter concept is challenged by the preliminary diapycnal diffusivity measurements of Polzin et al. (1997), which indicate that the low stratification, vigorous flow, and rough bathymetry of the ACC region may support very intense mixing over a broad depth range. Similarly high mixing rates in the deep Southern Ocean are suggested by the inverse analyses of Olbers and Wenzel (1989) and Sloyan and Rintoul (2000), and the property budget of Heywood et al. (2002), although these studies cover different geographical domains and yield disparate depth ranges of intensified diapycnal mixing.

The precise magnitude and density distribution of the zonally averaged meridional overturning of the Southern Ocean remain a contentious issue. In their [preWorld Ocean Circulation Experiment (WOCE)] basinscale inverse analysis, Sloyan and Rintoul (2001) estimated a net overturning of approximately $50 \mathrm{~Sv}(\mathrm{~Sv} \equiv$ $10^{6} \mathrm{~m}^{3} \mathrm{~s}^{-1}$ ) across $30^{\circ}-40^{\circ} \mathrm{S}$ concentrated below $\gamma^{n}=$ $27.4 \mathrm{~kg} \mathrm{~m}^{-3}\left[\gamma^{n}\right.$ is the neutral density variable of Jackett and McDougall (1997)], with northward and southward transport below and above $\gamma^{n}=28.0 \mathrm{~kg} \mathrm{~m}^{-3}$, respectively. Speer et al. (2000) contended that the density distribution of this overturning is qualitatively consistent with observations of significant meridional potential vorticity gradients in the UCDW layer (defined as $27.35<\gamma^{n}<28.0 \mathrm{~kg} \mathrm{~m}^{-3}$ ) and presented these as evidence of eddies driving the southward export of UCDW across the ACC. A weaker overturning of roughly $32 \mathrm{~Sv}$ across $30^{\circ} \mathrm{S}$ was obtained by Ganachaud and Wunsch (2000) in an inverse box model of the WOCE hydrographic dataset, with southward export in the $27.7<\gamma^{n}<28.1 \mathrm{~kg} \mathrm{~m}^{-3}$ class and the northward return flow partitioned between the overlying and underlying layers (10 and $22 \mathrm{~Sv}$, respectively). Based on a thermodynamic argument, Bryden and Cunningham (2003) calculated a similar cross-ACC overturning of $28 \mathrm{~Sv}$ (of which $11 \mathrm{~Sv}$ returned northward as a winddriven Ekman transport and $17 \mathrm{~Sv}$ as Antarctic Bottom Water) and suggested that the difference between the overturning rate and the Ekman transport was due to the eddies creating a meridional circulation larger than that driven directly by the wind. Gille (1999) conducted the only inverse analysis to date focusing on the subbasin-scale evolution of the ACC. She observed a barely significant northward flow of surface and intermediate waters $\left(\gamma^{n}<27.6 \mathrm{~kg} \mathrm{~m}^{-3}\right)$ and southward flow of deep water $\left(27.6<\gamma^{n}<28.2 \mathrm{~kg} \mathrm{~m}^{-3}\right)$ through the northern edge of the model domain in the southeast Pacific, and extrapolated those values circumpolarly to obtain a lower limit on the cross-ACC meridional overturning of 20-55 Sv.

The little information available on the zonal distribution of the cross-ACC meridional overturning has been provided by observational estimates of the heat flux signature of the overturning, which is considerably easier to detect than the associated mass fluxes. According to a number of atmospheric and basin-scale 


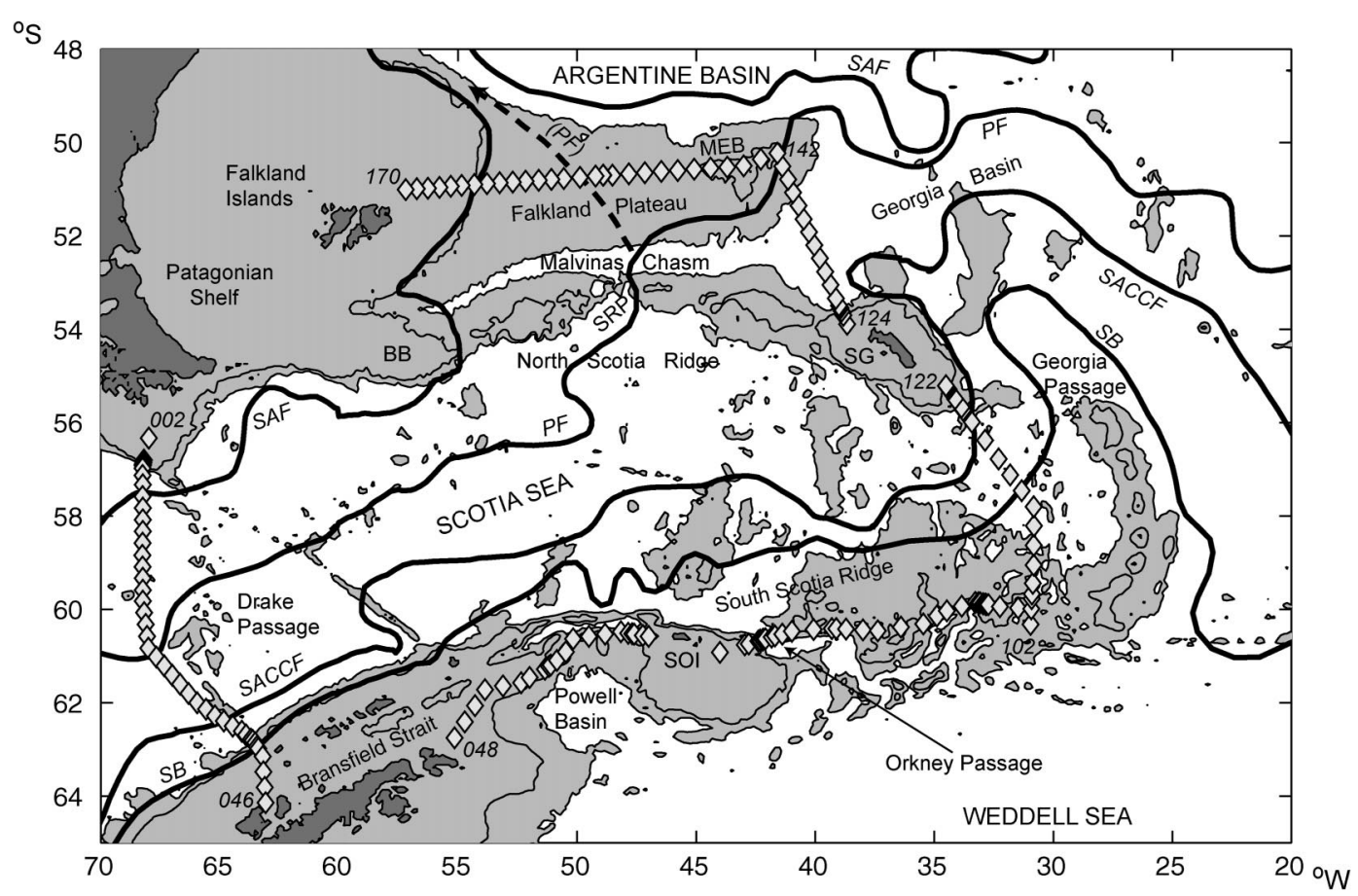

FIG. 1. Bathymetric configuration (isobaths 1500 and $3000 \mathrm{~m}$ ) in the region of the Scotia Sea (Smith and Sandwell 1997). ALBATROSS station locations (diamonds) and numbering are shown. Climatological positions of the ACC fronts (SAF, PF, and SACCF) and its southern boundary, such as defined by Orsi et al. (1995) and modified by Naveira Garabato et al. (2002a), are superimposed. The dashed line depicts the trajectory of a jet carrying PF waters over the Falkland Plateau (see Arhan et al. 2002). The following topographic features are indicated by their initials: Maurice Ewing Bank (MEB), Burdwood Bank (BB), Shag Rocks Passage (SRP), South Georgia (SG), and South Orkney Islands (SOI).

analyses [see Ganachaud and Wunsch (2003) for a review], between 0.4 and 1.2 PW are transported southward into the Southern Ocean across $40^{\circ} \mathrm{S}$. This southward heat transport is concentrated in the Indian Ocean with smaller northward heat fluxes in the Pacific and Atlantic sectors. Farther south, studies of the oceanic heat balance have inferred an oceanic heat loss of 0.2$0.65 \mathrm{PW}$ south of about $60^{\circ} \mathrm{S}$ (e.g., deSzoeke and Levine 1981; Gordon and Owens 1987), suggesting a southward heat flux of that magnitude across the ACC with a potentially important eddy contribution. In support of this conjecture, significant correlations between crossstream velocity and temperature anomaly of the required sign and magnitude have been observed in moored current meter records over the 400-3400-m depth range (e.g., Phillips and Rintoul 2000) and Lagrangian measurements at $900 \mathrm{~m}$ from ALACE floats (Gille 2003). These sparse observations hint at some proportionality between the cross-ACC heat flux and eddy kinetic energy, a relationship that had been previously assumed by Keffer and Holloway (1988) and Stammer (1998) in estimating eddy heat fluxes from altimeter data. A contrasting result was obtained by Gille (1999), whose inverse analysis failed to detect a significant change in the zonal heat flux associated with the subantarctic front (SAF) and polar front (PF) as the ACC crosses the southeast Pacific despite substantial alongstream variability in eddy kinetic energy.

In this study, we follow in the footsteps of Gille (1999) and construct a subbasin-scale inverse box model of the ACC that concurrently determines the different elements of the alongstream and overturning circulations, allowing their nature and interrelationship to be investigated. We focus on the Scotia Sea, a relatively small region of complex bathymetry in the southwest Atlantic (Fig. 1) believed to play a role of disproportionate relevance in the overturning of the Southern Ocean. A number of factors are key to this belief. First, the Scotia Sea has an important function in interocean exchange: physical processes in the Scotia Sea condition fluxes between the South Pacific and South Atlantic, by virtue of the region acting as a gateway between the two oceans. An example is the pronounced equatorward loop of the northern ACC in the western Scotia Sea (Fig. 1), which drives a direct transfer of South Pacific waters to the deep western boundary current of the subtropical South Atlantic (Arhan et al. 2002). Newly formed AAIW with sources in the southeast Pacific follows this route toward the South Atlantic subtropical gyre and experiences considerable cooling and freshening along the way (Piola and Gordon 1989). Air-sea interaction, the vigorous eddy field of the northwestern 
Scotia Sea and topographically enhanced diapycnal mixing as SAMW and AAIW flow along the rugged continental slope off southern Patagonia have been identified as possible causes of AAIW modification (Talley 1996).

Further, the Scotia Sea hosts the initial, most intense stages of the interaction between the ACC and the cyclonic Weddell gyre, the northern limb of which transgresses the South Scotia Ridge (Fig. 1) and injects newly ventilated Weddell waters into the Scotia Sea. This leads to an abrupt modification of the structure and water mass properties of the deep ACC (Naveira Garabato et al. 2002a) with potentially important repercussions for the fluxes associated with the current. The mixing mechanism behind this modification is yet to be determined. Locarnini et al. (1993) pointed out that diapycnal mixing between the CDW in the ACC and Weddell Sea Deep Water (WSDW) may be promoted by the juxtaposition of the two water masses in the Scotia Sea. WSDW is a variety of Antarctic Bottom Water formed in the Weddell Sea, and its most recently ventilated elements find in the Scotia Sea a preferential pathway to escape the Weddell basin (Gordon et al. 2001; Naveira Garabato et al. 2002a,b). An alternative view was presented by Whitworth et al. (1994), who emphasized the possible role of CDW and shelf water mixtures in the WeddellScotia confluence (a quasi-zonal, well-ventilated band of low stratification extending along the northern rim of the Weddell gyre from the Antarctic Peninsula) in ventilating the $\mathrm{CDW}$ in the ACC along isopycnals.

The paper is structured as follows. Section 2 presents the measurements entering the inverse model and the model formulation. The model behavior and the sensitivity of the solution are described in section 3. Section 4 discusses the time-mean state of the Scotia Sea circulation characterized by the solution, with particular attention to ACC processes. The consistency of the model diagnostics with present views of the circulation in the Scotia Sea and the broader Southern Ocean is examined. The main conclusions of the study are synthesized in section 5. [Note that additional water masses referenced in this paper are the Subantarctic Surface Water (SASW) and the Antarctic Surface Water (AASW).]

\section{Inverse model design}

\section{a. Dataset, domain, and layers}

The inverse model domain is a single box bounded by the Antarctic Large-Scale Box Analysis and the Role of the Scotia Sea (ALBATROSS) cruise track along the rim of the Scotia Sea region (Fig. 1). The dataset used in this study comprises 165 finely spaced hydrographic stations conducted between 18 March and 21 April 1999, and so the data are quasi-synoptic as compared with oceanic timescales of baroclinic variability. At each station, a suite of parameters (including temperature,
TABLE 1. Model layer definitions and approximate equivalences with water masses.

\begin{tabular}{ccc}
\hline \hline Layer & Upper interface $\gamma^{n}\left(\mathrm{~kg} \mathrm{~m}^{-3}\right)$ & Water mass \\
\hline 1 & Surface & SASW \\
2 & 26.80 & \\
3 & 26.90 & \\
4 & 27.00 & SAMW \\
5 & 27.10 & \\
6 & 27.20 & AAIW \\
7 & 27.30 & AASW \\
8 & 27.40 & \\
9 & 27.50 & \\
10 & 27.60 & \\
11 & 27.70 & \\
12 & 27.80 & \\
13 & 27.90 & \\
14 & 28.00 & \\
15 & 28.05 & \\
16 & 28.10 & \\
17 & 28.15 & WSDW \\
18 & 28.20 & \\
19 & 28.26 & \\
20 & 28.31 & \\
21 & 28.35 & \\
\hline
\end{tabular}

salinity, pressure, dissolved oxygen, phosphate, and silicate) were measured. Velocity profiles were obtained on station with a lowered acoustic Doppler current profiler (LADCP), operated in both water-tracking and bottom-tracking mode. Failure of the LADCP in the first 10 stations of northern Drake Passage (stations 2-11) motivated the use of vessel-mounted ADCP (VMADCP) data in that region. All ADCP data were detided using version 3.1 of the Oregon State University global tidal model (Egbert et al. 1994). Details of the data collection and analysis methods are given in the cruise report (Heywood and Stevens 2000), and a complete description of the hydrographic observations during ALBATROSS is provided by Naveira Garabato et al. (2002a). Arhan et al. (2002) and Naveira Garabato et al. (2002b) present the LADCP measurements along the transect between South Georgia and the Falkland Islands and that over the South Scotia Ridge, respectively.

The model is formulated in terms of 21 layers defined using the neutral density variable $\gamma^{n}$. Layer definitions and approximate equivalences with water masses are listed in Table 1. Figure 2 illustrates the geometry of the layers and water masses in relation to the potential temperature distribution.

\section{b. Model procedure}

The basic model procedure is that of the steady geostrophic box inversions characterized by Wunsch (1996). Using thermal wind balance, the velocity field (relative to an arbitrary reference level) along the rim of the model domain is calculated from the ALBA- 
TROSS temperature and salinity data. The model relies on the assumption that the large-scale thermal wind transports observed during the cruise are representative of the time-mean values to a good approximation. With this premise, full-depth and layer-specific conservation of mass, heat, and salt (expressed in terms of volume, potential temperature, and salinity, respectively) is enforced within specified uncertainties to determine four types of unknowns:

1) A depth-independent adjustment (the reference velocity $b$ ) to the relative velocity field at each station pair (162 unknowns).

2) A wind-driven Ekman velocity $\bar{v}^{\mathrm{Ek}}$ (where ${ }^{-\mathrm{EK}}$ indicates an exponential-decay-weighted mean over the Ekman layer) at each station pair (162 unknowns). Following Sloyan and Rintoul (2001), we assume the depth of the Ekman layer, $h_{\mathrm{Ek}}$, to be $60 \mathrm{~m}$ for the entire model domain. Ekman property fluxes at any station pair are calculated as the product of $\bar{v}^{\mathrm{Ek}}$ and the identically weighted mean property value over the Ekman layer. The resulting fluxes are added to the shallowest layer at that station pair. This approach implicitly assumes that the measured Ekman layer properties are representative of the annual mean values to a good approximation [confirmed by reference to the Hydrographic Atlas of the Southern Ocean (HASO), Olbers et al. (1992)] and that they can be combined with the annual-mean wind stress to obtain annual-mean Ekman property fluxes through the sides of the box.

3) A diapycnal velocity $w^{*}$ in the ocean interior (where "interior" refers to the entire water column beneath the surface, including the upper-ocean mixed layer) for each layer interface and each property (60 unknowns). Using property-specific diapycnal velocities at each layer interface has been shown to be an effective parameterization of net diapycnal fluxes in inverse models (McIntosh and Rintoul 1997; Sloyan and Rintoul 2000).

4) A surface diapycnal flux $F$, driven by air-sea interaction, for each outcropping layer interface and each property (60 unknowns); and a net air-sea heat exchange $M_{\theta}$ for each outcropping layer (21 unknowns). The details of this formulation of air-sea interaction are presented in the appendix.

The resulting conservation statements take the form

$$
\begin{gathered}
\sum_{j=1}^{N} \Delta x_{j}\left[\int_{p_{m}}^{p_{m+1}} \rho c\left(v_{r}+b\right)\left(\frac{\partial p}{\partial z}\right)^{-1} d p\right. \\
\left.+\bar{\rho}^{\mathrm{Ek}} \bar{c}^{\mathrm{Ek}} \overline{\boldsymbol{v}}^{\mathrm{Ek}} h_{\mathrm{Ek}}\right]_{j} \\
-\left[w_{c}^{*} A \overline{\rho c}^{A}\right]_{m}+\left[w_{c}^{*} A \overline{\rho c}^{A}\right]_{m+1} \\
+\left[F_{c}\right]_{m}-\left[F_{c}\right]_{m+1} \\
+\left[M_{c}\right]_{m+1}+n_{c, m+1}=0,
\end{gathered}
$$
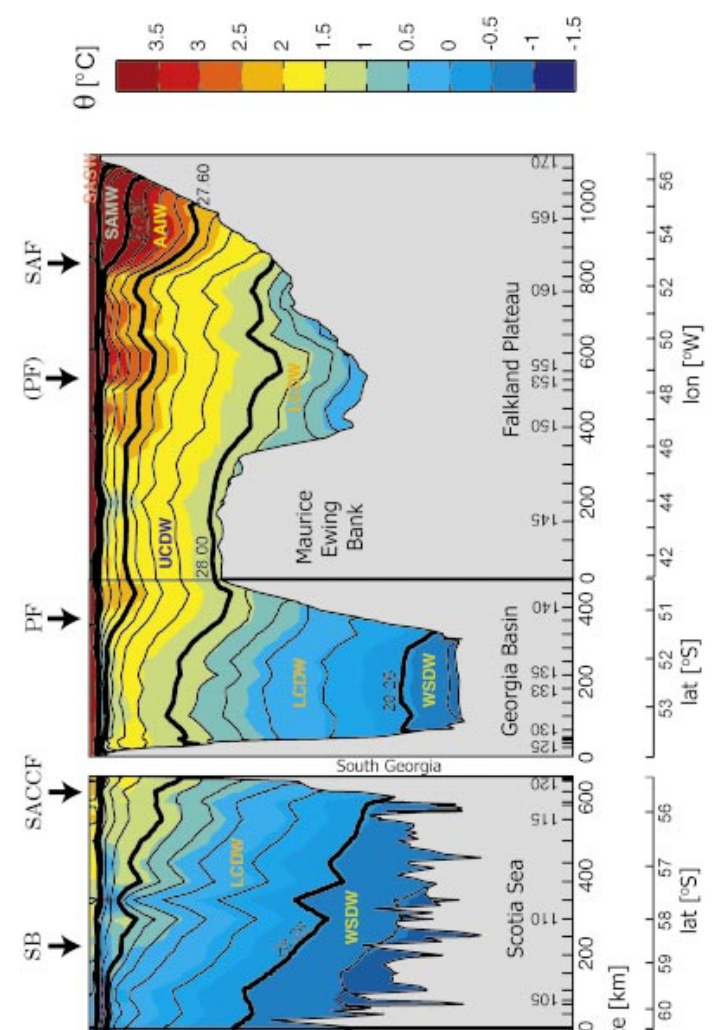

婇

$\stackrel{乛}{\Xi}$

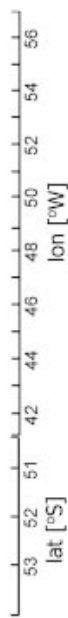

을

范

䓂希

है

跣

.

苛

4 过

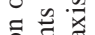

䒠

늘

纯

త్ Ð

证

鞄

ธ

范哭

원

司禹

कิ

品

금 
where $j$ and $m$ are station pair and layer interface indices, respectively, $N$ is the total number of station pairs, $\Delta x$ is the station pair spacing, $p$ is pressure, $\rho$ is potential density, $c$ is property concentration, $v_{r}$ is relative velocity, $A$ is the layer interface area within the model domain, ${ }^{A}$ denotes an average over area $A$, the operators []$_{j}$ and []$_{m}$ indicate evaluation of an expression at station pair $j$ and layer interface $m$, respectively, and $n_{c, m+1}$ refers to noise in the conservation equation for property $c$ and layer $m+1$.

Two additional constraints are included in the model. First, near-zero $(0 \pm 0.5 \mathrm{~Sv})$ net export of WSDW to the Pacific Ocean is prescribed (Orsi et al. 1999) and, second, a small net transport $(0.5 \pm 1 \mathrm{~Sv})$ of the same water mass is allowed to enter the Malvinas Chasm (Naveira Garabato et al. 2002a). We further impose weak full-depth conservation of silicate, and conservation of the tracer $\mathrm{PO}_{4}^{*}\left(\mathrm{PO}_{4}^{*}=\mathrm{PO}_{4}+\mathrm{O}_{2} / 175-1.95\right.$ $\mu \mathrm{mol} \mathrm{kg}{ }^{-1}$ (Broecker et al. 1998) in the layers that do not outcrop in the winter mixed layer (layers 16-21). Prior to this, the bottle measurements of silicate and $\mathrm{PO}_{4}^{*}$ are mapped onto the much finer (2 dbar) vertical grid of the CTD data using the optimal estimation algorithm of Roemmich (1983) with $\gamma^{n}$ as the vertical coordinate, resulting in negligible interpolation errors. The diapycnal advection terms are not explicitly represented in the $\mathrm{PO}_{4}^{*}$ conservation equations.

The conservation equations (1) for potential temperature, salinity, and $\mathrm{PO}_{4}^{*}$ are formulated in terms of property anomalies, obtained by subtracting the mean property value along the rim of the model domain. This improves the conditioning of the problem by reducing the impact of noisy mass flux divergences on the property flux divergences, effectively resulting in a higher rank model equation matrix (McIntosh and Rintoul 1997; Ganachaud 1999). The anomaly formulation, however, is not applied to silicate for technical reasons discussed by Ganachaud (1999).

An initial estimate of the unknowns is specified to guide the model solution. At each station pair, the reference velocity is initialized by performing a least squares fit of the geostrophic shear profile to the average detided water-track LADCP profile (the exception being the 10 northernmost station pairs at Drake Passage, where VM-ADCP data are used instead); the Ekman velocity is calculated from the annual-mean wind stress field of the Southampton Oceanography Centre (SOC) climatology (Josey et al. 1998). The diapycnal velocities for all variables are initialized as zero, and the mean potential temperature and salinity at each interface are extracted from the Special Analysis Center Hamburg climatology (Gouretski and Jancke 1998). Surface diapycnal fluxes of volume, potential temperature, and salinity are initially estimated using the formulation in the appendix. This formulation is applied to seasonally averaged maps of wind stress, net surface heat flux, and net evaporation from the SOC climatology combined with seasonal maps of surface density, temperature and salinity [e.g., plates 77-78 in Olbers et al. 1992)], and weighted-mean potential temperature and salinity in the Ekman layer, constructed from the HASO station dataset using an optimal interpolation algorithm.

Before inversion, the model equation matrix is weighted by the inverse of the square root of the a priori equation covariance matrix (row weighting) and by the square root of the a priori solution covariance matrix (column weighting). This set of weights parameterizes the noise term $n_{c, m+1}$ in (1). In the absence of prior knowledge of the full covariance matrices, we take both as diagonal. Volume conservation equations are weighted by the inverse of the a priori estimate of the uncertainty in the equation. Other conservation equations are normalized by the layer-mean absolute property value and weighted by the inverse of the a priori estimate of the uncertainty in the normalized equation. Following Ganachaud (1999), we assume that the dominant uncertainty in the conservation equations arises from the deviation of the baroclinic property transports at the time of observation from their true mean values over the period of representativeness of the model (the late 1990s, possibly longer) with a secondary contribution from internal wave noise. The selected a priori uncertainties in the volume conservation equations are listed in Table 2.

For the model layers corresponding to water masses flowing eastward through Drake Passage (layers 1-18) and the full-depth expression, the error in volume conservation induced by baroclinic variability is estimated from six repeats $(1993,1994,1996,1997,1998,1999$, and 2000, all in austral spring or summer) of the WOCE SR1b section across eastern Drake Passage (Cunningham et al. 2003), which captures the bulk of the transport into the Scotia Sea within those layers. The standard deviation of the baroclinic layer volume transport is adopted as an estimate of that error for layers 5-18 and full depth. For layers 1-4, which encompass the surface water and much of the SAMW in northern Drake Passage and the volumes of which are strongly affected by the seasonal cycle in atmospheric buoyancy forcing, the range of the baroclinic layer volume transport is considered instead. For the WSDW class (layers 19-21) the error in volume conservation is estimated by reference to the variability in the WSDW transport over the South Scotia Ridge in a fine-resolution numerical model of the region (Schodlok et al. 2002) with an additional contribution from the uncertainty in the transport through bottom triangles within the deep passages of the ridge [see Naveira Garabato et al. (2002b) for a discussion of this error]. The error in full-depth volume conservation due to internal wave noise is assumed to be implicit in the WOCE SR1b transport variability. The a priori uncertainty in the conservation of properties other than volume is estimated as double the product of the a priori error in mass conservation and the standard deviation of property variations within the relevant layer (Table 2 ). This is an ad hoc best guess proposed by Ganachaud 
TABLE 2. A priori errors in the volume conservation equations for model layers (generally defined by the standard deviation of the layer volume transports in six repeats of the WOCE SR1b section, with exceptions marked by the superscripts), and layer mean and standard deviation of potential temperature $(\theta)$ and salinity $(S)$ in ALBATROSS. Figures used in calculating the a priori errors in the $\theta$ and $S$ conservation equations (see section 2 b for an explanation of how this is done) are shown in boldface type.

\begin{tabular}{|c|c|c|c|}
\hline Layer & Error (Sv) & Mean $\pm \operatorname{std} \operatorname{dev} \theta\left({ }^{\circ} \mathrm{C}\right)$ & Mean $\pm \operatorname{std} \operatorname{dev} S$ \\
\hline 1 & $\mathbf{3 . 0 ^ { a , b }}$ & $6.387 \pm \mathbf{0 . 7 4 5}$ & $33.857 \pm \mathbf{0 . 1 2 3}$ \\
\hline 2 & $0.9^{\mathrm{b}}$ & $5.211 \pm \mathbf{0 . 9 6 9}$ & $33.867 \pm \mathbf{0 . 1 3 8}$ \\
\hline 3 & $2.3^{\mathrm{b}}$ & $4.928 \pm \mathbf{0 . 9 9 5}$ & $33.949 \pm \mathbf{0 . 1 3 1}$ \\
\hline 4 & $2.2^{\mathrm{b}}$ & $3.965 \pm \mathbf{1 . 0 8 7}$ & $33.920 \pm \mathbf{0 . 1 4 4}$ \\
\hline 5 & 1.6 & $4.317 \pm \mathbf{1 . 2 4 9}$ & $34.074 \pm \mathbf{0 . 1 5 3}$ \\
\hline 6 & 1.4 & $3.423 \pm \mathbf{1 . 2 4 0}$ & $34.059 \pm \mathbf{0 . 1 4 1}$ \\
\hline 7 & 1.2 & $2.826 \pm \mathbf{1 . 2 6 0}$ & $34.099 \pm \mathbf{0 . 1 3 4}$ \\
\hline 8 & 1.9 & $2.396 \pm \mathbf{1 . 1 7 9}$ & $34.152 \pm \mathbf{0 . 1 2 1}$ \\
\hline 9 & 1.0 & $2.252 \pm \mathbf{1 . 1 0 5}$ & $34.248 \pm \mathbf{0 . 1 1 4}$ \\
\hline 10 & 1.0 & $2.232 \pm \mathbf{1 . 1 3 0}$ & $34.361 \pm \mathbf{0 . 1 0 9}$ \\
\hline 11 & 1.1 & $1.990 \pm \mathbf{1 . 2 0 4}$ & $34.452 \pm \mathbf{0 . 1 1 3}$ \\
\hline 12 & 0.7 & $1.887 \pm \mathbf{1 . 2 3 8}$ & $34.562 \pm \mathbf{0 . 1 1 5}$ \\
\hline 13 & 1.0 & $1.678 \pm \mathbf{1 . 1 3 6}$ & $34.652 \pm \mathbf{0 . 1 0 5}$ \\
\hline 14 & 0.5 & $1.412 \pm \mathbf{0 . 9 6 0}$ & $34.688 \pm \mathbf{0 . 0 8 8}$ \\
\hline 15 & 0.3 & $1.164 \pm \mathbf{0 . 7 6 2}$ & $34.697 \pm \mathbf{0 . 0 7 0}$ \\
\hline 16 & 0.1 & $0.857 \pm \mathbf{0 . 5 0 8}$ & $34.694 \pm \mathbf{0 . 0 4 8}$ \\
\hline 17 & 0.5 & $0.588 \pm \mathbf{0 . 2 7 5}$ & $34.692 \pm \mathbf{0 . 0 2 8}$ \\
\hline 18 & 0.7 & $0.261 \pm \mathbf{0 . 1 9 8}$ & $34.687 \pm \mathbf{0 . 0 2 2}$ \\
\hline 19 & $0.5^{\mathrm{c}}$ & $-0.102 \pm \mathbf{0 . 1 2 3}$ & $34.668 \pm \mathbf{0 . 0 1 3}$ \\
\hline 20 & $0.5^{\mathrm{c}}$ & $-0.301 \pm \mathbf{0 . 0 5 2}$ & $34.660 \pm \mathbf{0 . 0 0 5}$ \\
\hline 21 & $0.3^{\mathrm{c}}$ & $-0.554 \pm \mathbf{0 . 0 2 4}$ & $34.648 \pm \mathbf{0 . 0 0 3}$ \\
\hline Full depth & $8.1^{\mathrm{a}}$ & $1.235 \pm \mathbf{1 . 4 1 0}$ & $34.581 \pm \mathbf{0 . 1 3 9}$ \\
\hline
\end{tabular}

a An upper bound estimate of $3 \mathrm{~Sv}$ for the Patagonian shelf transport is added in quadrature to the value determined from WOCE SR1b.

b The range (rather than the std dev) of WOCE SR1b layer transports is used.

c Estimated by reference to the numerical model results of Schodlok et al. (2002).

and Wunsch (2000) in which the factor of 2 accounts for possible correlations between the section-averaged and mesoscale components of the noise in the property conservation equation. The lack of an explicit representation of the volume, potential temperature, salinity, and silicate transports (contained within layer 1) over the unsampled Patagonian shelf (Fig. 1) is accounted for in the uncertainty of the full-depth and layer-1 equations. This is done by reference to an existing estimate of the northward volume transport over the shelf (approximately $1 \mathrm{~Sv}$, Rivas 1994) and the annual-mean property values at the shelf in HASO. A contribution to the a priori error in the layer $\mathrm{PO}_{4}^{*}$ conservation equations from the unrepresented diapycnal advection of this tracer is also calculated.

All unknowns are weighted by their a priori uncertainty divided by the column norm. In the case of the reference velocities, Ekman velocities and diapycnal velocities, this is equivalent to multiplying by the square root of the uncertainty and dividing by the square root of the station pair area, Ekman layer station pair area, and layer interface area, respectively. For the surface diapycnal fluxes, it involves multiplying by the square root of the uncertainty. The a priori uncertainty in the reference velocity has two independent contributions. That from the referencing error is estimated as $2 \times 10^{-2}$ $\mathrm{m} \mathrm{s}^{-1}\left(4 \times 10^{-2} \mathrm{~m} \mathrm{~s}^{-1}\right)$ for station pairs initialized by reference to LADCP (VM-ADCP) data (Arhan et al. 2002; Naveira Garabato et al. 2002b). The other arises from the temporal variability of the reference velocity and is quantified as $1 \times 10^{-2} \mathrm{~m} \mathrm{~s}^{-1}$ by reference to the observed temporal variability of the mean deep flow at Drake Passage (Bryden and Pillsbury 1977; Whitworth et al. 1982; Cunningham et al. 2003) with higher values over active tidal regions (notably, the continental shelf and environs). The a priori uncertainty in the Ekman velocity is tentatively chosen as $1 \times 10^{-3} \mathrm{~m} \mathrm{~s}^{-1}$ (equivalent to a wind stress magnitude uncertainty of around $20 \%$ in the SOC climatology) and that in the diapycnal velocities as $10^{-5} \mathrm{~m} \mathrm{~s}^{-1}$, near the upper end of the range of observed deep-ocean mixing rates [see Orsi et al. (1999) for a review]. The a priori uncertainty in the surface diapycnal fluxes is set to $50 \%$, an exploratory value characterizing biases in the SOC climatology and the seasonal maps of the surface hydrography from HASO.

\section{The standard solution}

The row- and column-weighted system of equations is solved by singular value decomposition (Wunsch 1996). The rank of the solution (57, out of 75 equations) is selected to yield a dynamically acceptable solution in which perturbations to the initial estimates of the unknowns remain within one a priori standard deviation and equation residuals are indistinguishable from zero within two a posteriori standard deviations ${ }^{1}$ (Fig. 3). The two exceptions to the latter are the large salinity anomaly equation residual of layer 1 , which may be caused by the absence of a northward transport of low salinity water over the Patagonian Shelf in the model, and the potential temperature anomaly equation residual of layer 9, which is marginally larger than the two standard deviation error bar. The reference velocities in this standard solution are modified only minimally, with a mean (peak) perturbation of $\pm 7 \times 10^{-3}\left(3 \times 10^{-2}\right) \mathrm{m}$ $\mathrm{s}^{-1}$. The largest adjustments $\left(1.5-2 \times 10^{-2} \mathrm{~m} \mathrm{~s}^{-1}\right)$ are introduced over the continental shelf of northern Drake Passage (eastward), the shallow sector of the South Scotia Ridge near the Antarctic Peninsula (in both directions), the western region of the Orkney Passage (southward), the central part of the Georgia Basin (westward) and the region of the subantarctic front over the Falkland Plateau (southward). The model effects weak (approx-

\footnotetext{
${ }^{1}$ The posterior solution and equation covariance matrices are calculated in the framework of the Gauss-Markov formulation of the inverse problem (Wunsch 1996, p. 184). They are versions of the prior solution and equation covariance matrices that have been updated in accordance with the new information provided by the model equations, and include the null space (the part of the solution unresolved by the equations).
} 

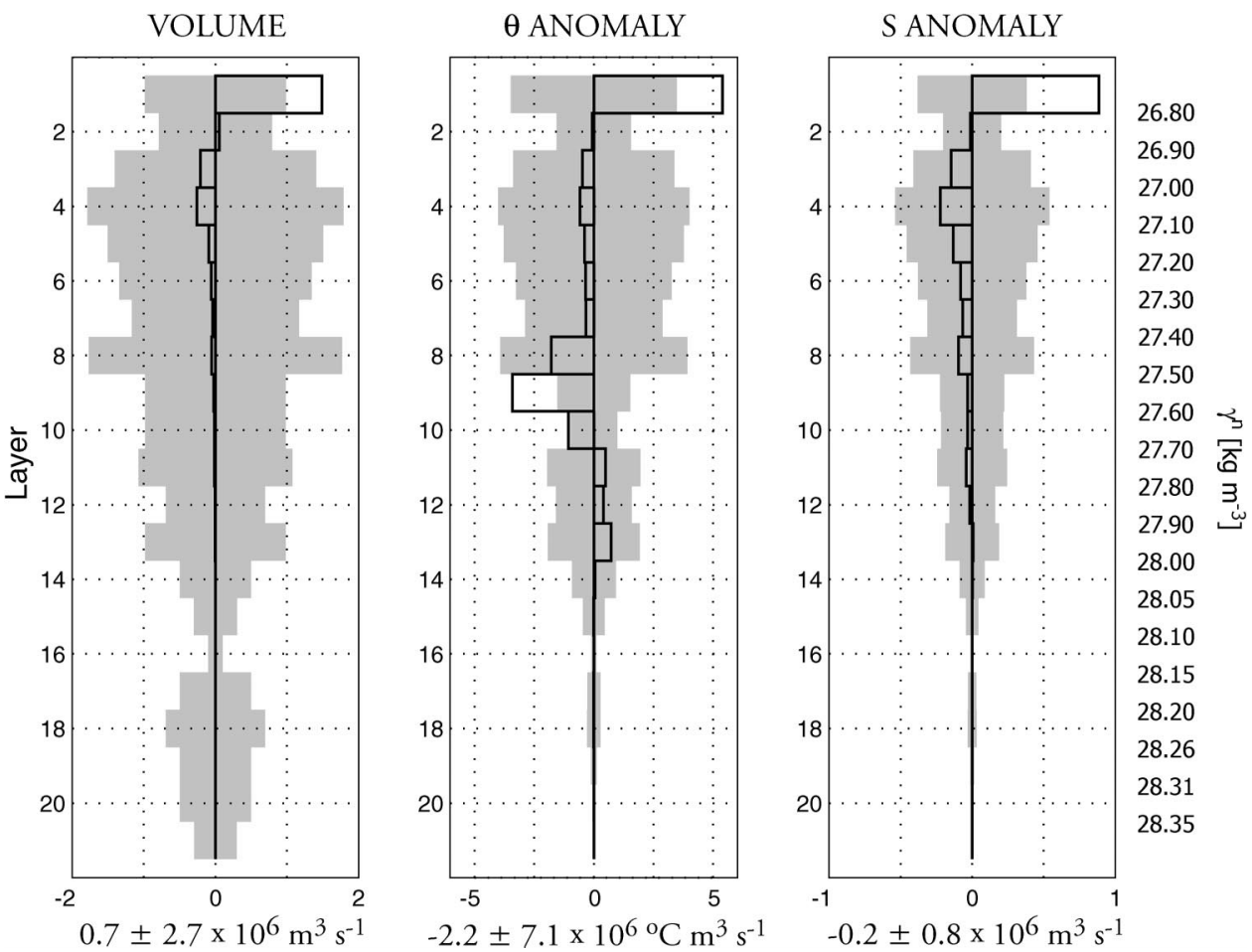

FIG. 3. Standard solution residuals of volume, potential temperature anomaly, and salinity anomaly in individual layers (bars). The shaded area gives the one standard deviation uncertainty. The full-depth residual and units are indicated below each graph.

imately $4 \times 10^{-3} \mathrm{~m} \mathrm{~s}^{-1}$ ) westward and southward biases, respectively, throughout the deep part of Drake Passage and the eastern part of the Falkland Plateau. The median magnitude of changes to Ekman velocities is $12 \%$, integrating to a peak Ekman transport into the domain altered by $17 \%$. The main adjustments to the initial values are introduced over northern Drake Passage (where the eastward Ekman transport is increased) and in areas of the Georgia Basin and the Falkland Plateau (where the northward Ekman transport is decreased). The magnitude and spatial distribution of these modifications change little if Ekman transports of properties other than volume are not considered in the conservation equations. The diagnosed diapycnal volume velocities have a median magnitude of $8 \times 10^{-7} \mathrm{~m} \mathrm{~s}^{-1}$, with similar values for potential temperature and salinity. Modifications to surface diapycnal fluxes reach values of $20 \%-40 \%$ at the lighter surfaces and decrease sharply with density with order $10 \%$ corrections to the net air-sea heat exchange terms.

The observation resolution matrix (e.g., Wunsch 1996, p. 165) indicates that the volume, potential temperature and salinity equations are well resolved, with the silicate and $\mathrm{PO}_{4}^{*}$ equations having a far lesser degree of independence. (Accordingly, suppressing the silicate and $\mathrm{PO}_{4}^{*}$ equations from the model produces a nearly identical solution.) Examination of the solution resolution matrix reveals that the resolution of interior diapycnal velocities and surface diapycnal fluxes is gen- erally satisfactory. However, individual reference velocities and Ekman velocities are poorly resolved, and the ability of the model to accurately determine lateral fluxes is restricted to the larger scales. This is a feature common to many inverse studies. A novel, advantageous aspect of our model in relation to previous works is the wide availability of full-depth direct current measurements along the rim of the model domain, which enables the initial estimate of the solution to be close to satisfying the model equations within a priori uncertainties (e.g., initial volume residuals are typically 1-3 Sv, both in individual layers and full depth). This circumstance suggests that, inasmuch as a snapshot of the flow averaged over a certain length scale may be representative of its true mean value, fluxes associated with length scales smaller than those resolved by the model (e.g., the scale of hydrographic zones of the ACC) may nevertheless be represented adequately in the model solution. This assumption is reinforced by the observation that the dominant mode of variability in the ACC is vertically coherent and equivalent barotropic (Sun and Watts 2001).

To evaluate the impact of the direct velocity observations in the solution, we conducted a series of experiments in which an initial level of no motion at the deepest common level between stations was prescribed in the ACC region (a common practice in inverse box models of the Southern Ocean). Over the South Scotia Ridge, the level of no motion was placed either at the 
deepest common level or at a middepth isopycnal (similarly to Locarnini et al. 1993). The solutions produced by these experiments appeared of poorer quality than the standard solution: there were larger residuals at the same rank, flux divergences in the hydrographic zones of the ACC between the inflow and outflow regions were accentuated, and the influx of WSDW over the South Scotia Ridge was reduced to a value inconsistent with observations (Gordon et al. 2001) and numerical studies (Schodlok et al. 2002). The latter reduction resulted in markedly decreased interior diapycnal fluxes at depth, although the broad qualitative structure of the diapycnal velocities was retained. Only by explicitly constraining the net volume transports of the two primary inflows to the Scotia Sea (the ACC at Drake Passage and the WSDW overflow at the South Scotia Ridge) did we succeed in recreating the bulk fluxes of the standard solution. This behavior emphasizes the importance of direct velocity observations (or transport estimates based on observations) in inverse box models using a crude, diagonal representation of the a priori covariance matrices and involving subpolar regions such as the Weddell gyre. There, the prevailing low stratification and reduced baroclinic shear lead to a circulation dominated by narrow, largely barotropic jets (Gordon et al. 2001; Naveira Garabato et al. 2002b) that cannot be reasonably approximated with a level of no motion. In this respect, our model differs from other inverse analyses that have incorporated direct velocity measurements and found them to have no significant impact on the solution (e.g., Gille 1999).

\section{The circulation of the Scotia Sea}

\section{a. Volume transport across the Scotia Sea rim}

The structure of the geostrophic velocity field (Fig. 4, upper panel) and the associated full-depth volume transport (Fig. 4, lower panel; a map synthesis of the volume transport field is provided in section 5) in the solution reflects the two inflows to the Scotia Sea. The net transport through Drake Passage is $138 \pm 13 \mathrm{~Sv}$ eastward of which $143 \pm 13 \mathrm{~Sv}$ are conveyed by the $\mathrm{ACC}^{2}$ and $5 \pm 1 \mathrm{~Sv}$ flow westward through the Bransfield Strait and along the Antarctic continental slope. The diagnosed net transport is consistent with the initial ADCP-based value of $148 \pm 14 \mathrm{~Sv}$ and with independent estimates from moored current-meter measurements (134 Sv, with an uncertainty of 15-27 Sv; Whitworth et al. 1982; Cunningham et al. 2003) and inverse analyses (e.g., $135 \mathrm{~Sv}$, with an uncertainty of $\pm 1 \mathrm{~Sv}$

\footnotetext{
2 Throughout this study, the ACC is defined as the region north of (and including) the southern boundary (SB) described by Orsi et al. (1995) (Fig. 3). At Drake Passage and the eastern Scotia Sea, the SB is thus located between stations 37 and 38 and 108 and 109, respectively. These locations coincide with a minimum in the volume transport difference between the inflowing and outflowing ACC within model layers 12-16, at which the ACC transport peaks (section 4b).
}

that does not account for baroclinic variability; Sloyan and Rintoul 2001). The transport into the model domain peaks at $159 \pm 15 \mathrm{~Sv}$ following the import of $19 \pm 7$ Sv of Weddell water over the South Scotia Ridge and a minor recirculation near the eastern end of the ridge. This suggests that a substantial fraction $(20 \%-40 \%)$ of the total Weddell gyre transport, estimated as approximately $40 \mathrm{~Sv}$ south of the ridge (Beckmann et al. 1999; Gordon et al. 2001), penetrates the Scotia Sea. The overflow transport is compatible (within error bars) with the LADCP-based estimate of $22 \pm 7 \mathrm{~Sv}$ and with the $7 \pm$ 6 Sv obtained by Naveira Garabato et al. (2002b) in an inverse box model of the western Weddell gyre.

Of the $159 \pm 15 \mathrm{~Sv}$ entering the Scotia Sea, $40 \pm$ $12 \mathrm{~Sv}$ leave the model domain south of South Georgia and a net $119 \pm 12$ Sv overflow the North Scotia Ridge into the Georgia and Argentine Basins. The latter value reflects the $129 \pm 21$ Sv estimated by Arhan et al. (2002) from the ALBATROSS LADCP data between South Georgia and the Falkland Islands. The eastward transport south of South Georgia is partitioned unevenly between the ACC $(30 \pm 10 \mathrm{~Sv})$ and the northern limb of the Weddell gyre $(10 \pm 7 \mathrm{~Sv})$, suggesting that there is a significant volume transfer from the gyre to the ACC in the Scotia Sea. As a consequence, the transport of the ACC outflowing the domain is $149 \pm 16 \mathrm{~Sv}$. (The increase in the ACC transport from the Drake Passage value is significant in the framework of the inverse mod$\mathrm{el}$, as the conservation equations constrain the standard deviation of the difference to be much smaller than the standard deviations of the individual ACC transport estimates.) The difference is principally accounted for by the incorporation into the ACC band of the bulk of the $5.9 \pm 1.7 \mathrm{~Sv}$ of WSDW that overflow the South Scotia Ridge, which amounts to approximately one-half of the total Antarctic Bottom Water production in the Weddell Sea (Naveira Garabato et al. 2002b). As specified in one of the model constraints, no measurable volume of WSDW overflows the sill of Drake Passage. The WSDW transport over the South Scotia Ridge diagnosed in this study is in good agreement with the LADCPbased and Weddell gyre inverse model estimates of Naveira Garabato et al. (2002b) $(6.7 \pm 1.7$ and $4.7 \pm 0.7$ Sv, respectively).

As well as in its net value, the full-depth transport of the ACC is dramatically modified in its horizontal structure as it crosses the Scotia Sea. In Drake Passage, the geostrophic velocity of the solution (Fig. 4, upper panel) reveals the presence of two clearly defined jets (associated with the SAF and PF) in the northern half of the ACC and a system of narrower, weaker current cores [linked to the southern ACC front (SACCF) and SB)] in the southern part of the current. This distribution of the flow is characteristic of the ACC at Drake Passage, although the SAF and PF jets can merge occasionally (Cunningham et al. 2003). The solution suggests that the major contributor to the ACC transport at Drake Passage is the PF jet $(80 \pm 7 \mathrm{~Sv})$, with the SAF and 


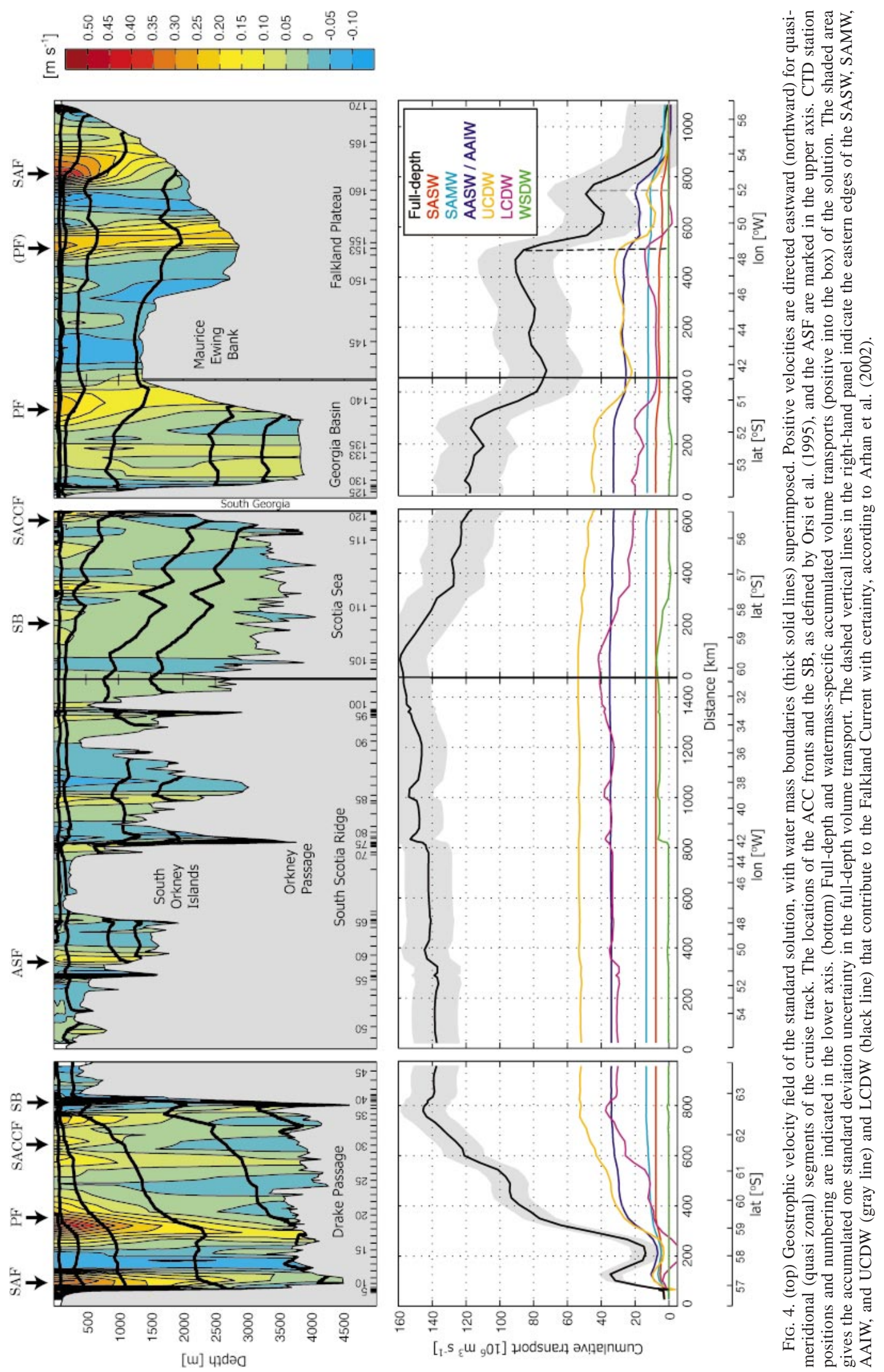


the ACC south of the PF providing $31 \pm 7$ and $46 \pm$ $8 \mathrm{~Sv}$, respectively (Fig. 4, lower panel).

When the ACC leaves the model domain, the structure of the geostrophic flow and full-depth transport is markedly different. The contribution of the SAF is larger (48 $\pm 4 \mathrm{~Sv}$ ), that of the PF is reduced ( $37 \pm 6 \mathrm{~Sv}$, of which approximately $20 \mathrm{~Sv}$ are supplied by a recirculation around the Maurice Ewing Bank), the transport of the ACC south of the PF is roughly unchanged (41 \pm 12 Sv), and there is a fourth current band centered at $49.5^{\circ} \mathrm{W}$ over the Falkland Plateau that accounts for 52 \pm 6 Sv. Naveira Garabato et al. (2002a) showed that this core is composed of waters entering the Scotia Sea on the northern flank of the PF, and Arhan et al. (2002) argued that the division of the PF transport in two branches occurs as a result of interaction with topography at the southern edge of the Falkland Plateau. The branching plays a crucial role in transferring water originating in the northern side of the PF at Drake Passage to the deep Falkland Current, which conveys it toward the subtropical gyre. Arhan et al. (2002) identified the elements of the Falkland Plateau overflow that feed the Falkland Current (indicated by the dashed lines in Fig. 4, lower panel): the entire water column at and west of the SAF (48 $\pm 4 \mathrm{~Sv}$ in the solution) and the LCDW class in the jet at $49.5^{\circ} \mathrm{W}(14 \pm 1 \mathrm{~Sv})$, with a possible or occasional contribution of lighter water within the jet $(23 \pm 4 \mathrm{~Sv})$ and a minor input of Southeast Pacific Deep Water (LCDW in layer 18) skirting the Maurice Ewing Bank $(1 \pm 1 \mathrm{~Sv})$. Adding the transports in the solution, a Falkland Current transport of 63-86( \pm 6$) \mathrm{Sv}$ (the range reflecting the inclusion or not of the $23 \pm 4$ Sv of UCDW and near-surface water transported by the jet at $\left.49.5^{\circ} \mathrm{W}\right)$ is obtained that is indistinguishable from the $63-83( \pm 10)$ Sv calculated by Arhan et al. (2002) using the ALBATROSS LADCP data or from Falkland Current transport estimates in the Argentine Basin (e.g., 88 Sv, Peterson 1992).

The wind-driven Ekman volume transport across the Scotia Sea rim (not shown) is negligibly small in relation to the geostrophic transport. There is a small (about 0.2 $\mathrm{Sv}$ ) Ekman convergence into the model domain that arises from an inflow of $1 \mathrm{~Sv}$, mostly occurring over the South Scotia Ridge, and a slightly smaller outflow $(0.8 \mathrm{~Sv})$ across the Falkland Plateau. In the SOC climatology, used to initialize the Ekman flow field, an Ekman divergence of approximately $0.2 \mathrm{~Sv}$ is suggested instead. The adjustment introduced by the model is insignificant.

\section{b. ACC watermass conversion in the Scotia Sea}

In the rather short (1500-2800 km) transit across the Scotia Sea, the density structure of the ACC volume transport undergoes a notable transformation. In Drake Passage (Fig. 5), the ACC transport is concentrated in layers 5-17 and peaks in layers 12-16 (27.80< $\gamma^{n}<$ $\left.28.15 \mathrm{~kg} \mathrm{~m}^{-3}\right)$. The latter span the interface between

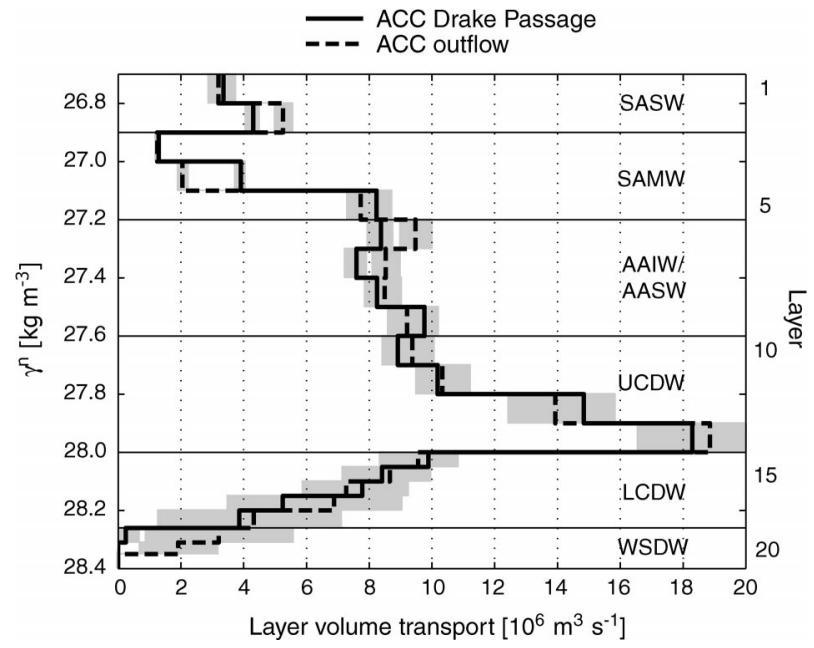

FIG. 5. Layer distribution of the ACC volume transport at Drake Passage (thick solid line) and the outflow region (dashed line). The shaded area gives the one standard deviation uncertainty in each layer transport. Water masses are labeled, and their boundaries are indicated by horizontal black lines.

UCDW and LCDW, lying in the 1000-3500-m depth range in the ACC core, between the SAF and PF. On average, there is a shift of the transport to higher densities as the ACC crosses the basin (Fig. 5), and the transport-weighted mean neutral density of the ACC increases from $27.65 \mathrm{~kg} \mathrm{~m}^{-3}$ at Drake Passage to 27.70 $\mathrm{kg} \mathrm{m}^{-3}$ on leaving the model domain. The largest layer transport differences occur within layers 17-20, which encompass the bulk of the Weddell water overflowing the South Scotia Ridge (Fig. 2), and in the SAMW and AAIW/AASW classes.

Many of the changes in the density structure of the ACC can be related to the interior diapycnal volume velocity $w_{V}^{*}$ profile diagnosed by the model for the entire domain (Fig. 6a). Vigorous upwelling is observed within the WSDW layer, peaking at the densest layer interface $\left[(7.4 \pm 1.8) \times 10^{-6} \mathrm{~m} \mathrm{~s}^{-1}\right]$ and decreasing upward to a near-zero value at the LCDW-WSDW boundary. Large downwelling rates of $(1.9 \pm 1.0) \times 10^{-6} \mathrm{~m} \mathrm{~s}^{-1}$ are inferred across the lower class of LCDW $\left(\gamma^{n}=\right.$ 28.15 and $28.20 \mathrm{~kg} \mathrm{~m}^{-3}$ ), above which the magnitude of the diapycnal velocity decreases and is not significantly different from zero within one standard deviation error bars.

The (significant) deep diapycnal volume velocity values in Fig. 6a are among the highest diagnosed in ocean basins, lending support to the picture of the Scotia Sea as a region of intense abyssal diapycnal mixing linked to the rough topography (Locarnini et al. 1993; Orsi et al. 1999; Heywood et al. 2002). In common with other direct and inverse estimates of diapycnal mixing elsewhere (e.g., Polzin et al. 1997; Sloyan and Rintoul 2000; Ganachaud and Wunsch 2000), the model indicates the occurrence of the most vigorous diapycnal mixing in the deeper part of the water column, peaking within a 

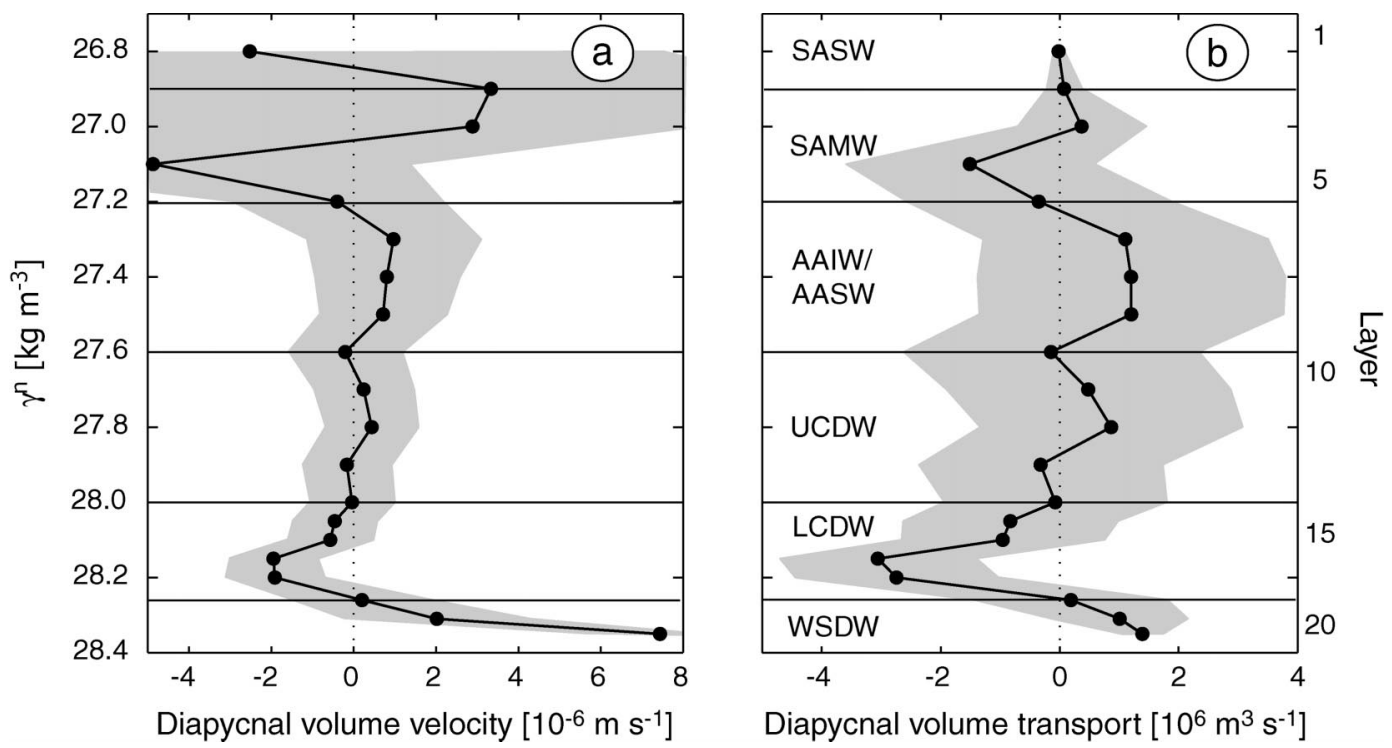

FIG. 6. (a) Interior diapycnal volume velocity and (b) associated diapycnal volume transport for the model domain in the solution. A positive velocity or transport is directed upward. The shaded area gives the one standard deviation uncertainty. Water masses are labeled, and their boundaries are indicated by horizontal black lines.

bathymetrically confined density class (Lower WSDW, $\left.\gamma^{n}>28.31 \mathrm{~kg} \mathrm{~m}^{-3}\right)$. Heywood et al. (2002) conducted a heat budget of Lower WSDW to calculate a diapycnal diffusivity of $(39 \pm 10) \times 10^{-4} \mathrm{~m}^{2} \mathrm{~s}^{-1}$ across its upper interface averaged over the Scotia Sea, corresponding approximately to an upwelling rate of $(6 \pm 1.5) \times 10^{-6}$ $\mathrm{m} \mathrm{s}^{-1}$. This value is significantly larger than the $(2.0 \pm$ 2.2) $\times 10^{-6} \mathrm{~m} \mathrm{~s}^{-1}$ found at the upper interface of Lower WSDW in the solution. Although the control volumes considered are slightly different in each exercise, the discrepancy may indicate that the initialization of the diapycnal volume velocity as zero motivated by our lack

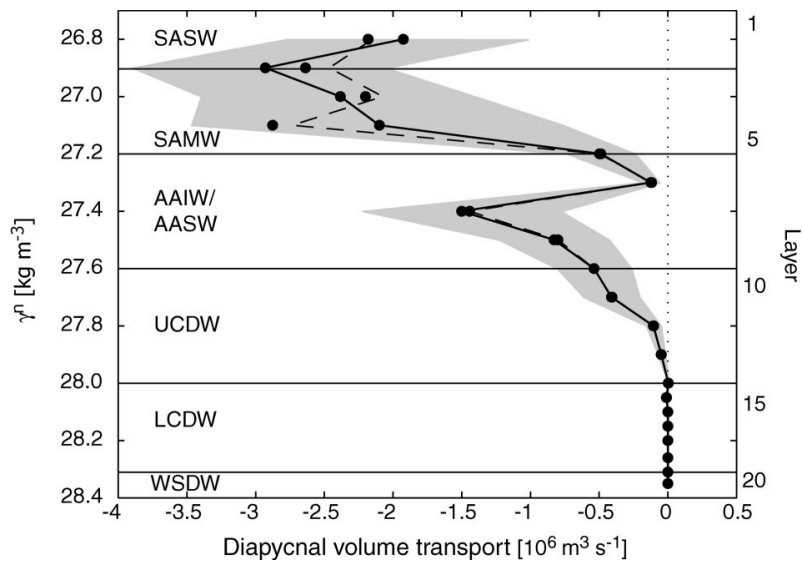

FIG. 7. Surface diapycnal volume transport for the model domain in the solution (thick solid line) and in the initial estimate from HASO and the SOC climatology (dashed line) (see section 2b). The shaded area gives the one standard deviation uncertainty of the former. A positive transport is directed toward increasing density. Water masses are labeled, and their boundaries are indicated by horizontal black lines. of knowledge of the regional properties of the mixing, introduces a bias toward a minimum mixing solution. Nevertheless, large and significant diapycnal volume velocities are diagnosed in LCDW layers found 1500$2000 \mathrm{~m}$ above the bottom over much of the model domain, suggesting that high mixing rates may extend a substantial distance above the topography. We note, however, that this general inference does not apply to the LCDW-WSDW interface, where there is a near-zero diapycnal volume velocity.

Figure $6 \mathrm{~b}$ shows the diapycnal volume fluxes associated with the diapycnal velocities described above. There is a net upwelling of $1 \pm 1.1 \mathrm{~Sv}$ of Lower WSDW into the overlying WSDW class in spreading from the South Scotia Ridge to the eastern Scotia Sea with no significant net exchange between the LCDW and WSDW layers. Invoking continuity, this is consistent with the observation that the WSDW transport within the outflowing ACC (5.1 $\pm 3.1 \mathrm{~Sv}$, Fig. 5) closely matches the WSDW import over the South Scotia Ridge $(5.9 \pm 1.7 \mathrm{~Sv})$. A convergence of about $4 \mathrm{~Sv}$ is inferred between the $\gamma^{n}=28.15 \mathrm{~kg} \mathrm{~m}^{-3}$ isopycnal and the top of the Lower WSDW layer, suggesting that mixing between relatively dense WSDW and light LCDW produces water of intermediate density. No significant interior diapycnal volume flux is indicated above $\gamma^{n}=$ $28.15 \mathrm{~kg} \mathrm{~m}^{-3}$.

Volume transport changes in UCDW, AAIW/AASW, and SAMW layers within the ACC are connected most clearly to diapycnal volume fluxes driven by air-sea interaction across isopycnals outcropping at the surface (Fig. 7). In the solution, this flux is negative (i.e., directed toward lower densities) throughout the model domain. (Note that layer interfaces with $\gamma^{n}>27.9 \mathrm{~kg} \mathrm{~m}^{-3}$ 


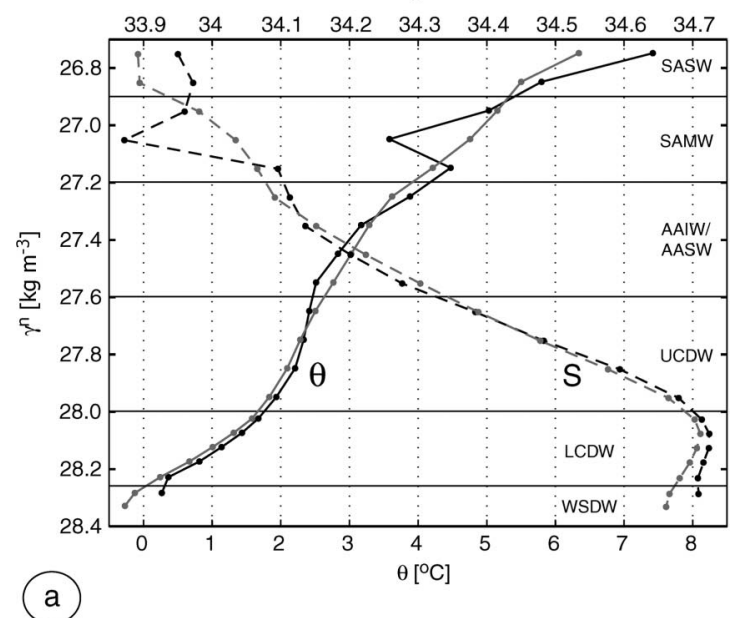

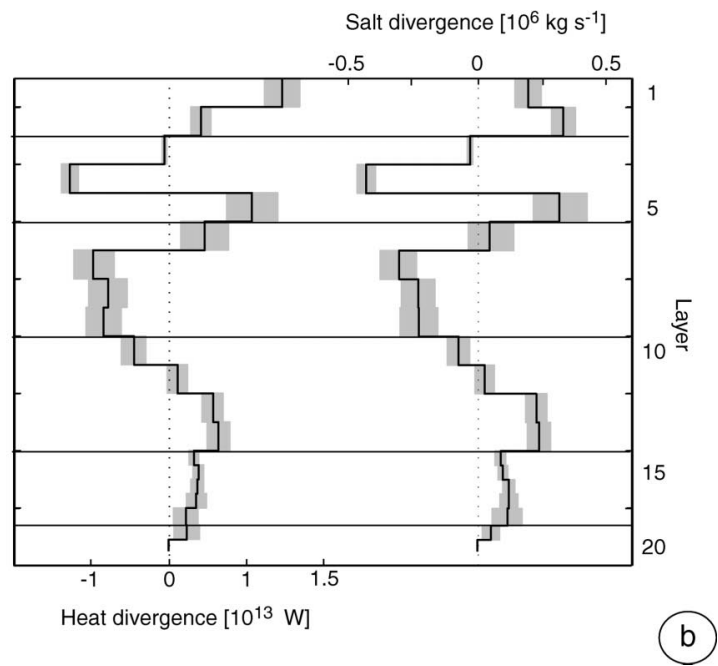

FIG. 8. (a) ACC volume-transport-weighted layer-mean potential temperature (solid lines) and salinity (dashed lines) at Drake Passage (black) and the outflow region (gray). (b) ACC layer heat and salt flux divergences in the Scotia Sea (the contribution from layer volume flux divergences has been subtracted). The shaded area gives the one standard deviation uncertainty. Water masses are labeled, and their boundaries are indicated by horizontal black lines.

rarely outcrop in the Scotia Sea.) The model suggests only small corrections to the initial surface diapycnal volume fluxes, indicating a high degree of consistency with the initial ADCP-referenced geostrophic flow. Inspection of the individual contributions of the air-sea heat flux, net evaporation, and wind stress terms to the initial surface diapycnal flux values calculated from climatological data suggests that the surface diapycnal volume flux in the solution is predominantly driven by the northward Ekman transport associated with the prevailing eastward wind stress for $\gamma^{n} \geq 27.4 \mathrm{~kg} \mathrm{~m}^{-3}$ and by the exchange of heat with the atmosphere at lower densities (not shown). The minimum (maximum) in the magnitude of the flux near $\gamma^{n}=27.3 \mathrm{~kg} \mathrm{~m}^{-3}\left(\gamma^{n}=\right.$ $26.9 \mathrm{~kg} \mathrm{~m}^{-3}$ ) appears to be induced by atmospheric cooling (heating) in the northern Scotia Sea during winter (summer).

As a result of the minimum near $\gamma^{n}=27.3 \mathrm{~kg} \mathrm{~m}^{-3}$, an Ekman-driven volume flux divergence of $1.4 \pm 0.7$ Sv occurs in layers 8-12, in the lower AAIW/AASW class and upper fraction of UCDW, which outcrop in the ACC sector to the south of the PF over most of the year. The bulk of that diapycnal transport converges in layer 7, in the core of AAIW/AASW, which outcrops in the northern Scotia Sea during the cooling season. This convergence is reflected in a surplus of water in layer 7 in the outflowing ACC (Fig. 5), whereas the similar transport increase in layer 6 appears to be linked to an uncertain conversion of SAMW to AAIW/AASW by the interior diapycnal volume flux (Fig. 6b). In layers $3-5$, spanning the SAMW class (which outcrops in the northern Scotia Sea in summer), there is a surface diapycnal volume flux divergence of $2.5 \pm 0.9 \mathrm{~Sv}$ concentrated in layer 5 that causes a deficit of SAMW in the outflowing ACC (this deficit is partially offset by an uncertain convergence of the interior diapycnal volume flux in that layer) and an excess of SASW.

\section{c. ACC heat and freshwater fluxes in the Scotia Sea}

In parallel with the increase in volume transport and general densification of the ACC, the heat and freshwater fluxes associated with the current are profoundly modified in the Scotia Sea. Figure 8a shows the volumetransport-weighted mean potential temperature and salinity of each layer in the inflowing and outflowing ACC. As anticipated by Naveira Garabato et al. (2002a), the entire CDW class denser than $\gamma^{n}=27.80 \mathrm{~kg} \mathrm{~m}^{-3}$ (layers 12-18), which accounts for $46 \%-49 \%$ of the ACC volume transport, cools by $0.08^{\circ}-0.14^{\circ} \mathrm{C}$ and freshens by $0.010-0.026$ in crossing the basin. In contrast, there is a pronounced warming (by $0.11^{\circ}-0.25^{\circ} \mathrm{C}$ ) and salinification (by 0.004-0.026) in the uppermost UCDW layer and over much of the AAIW/AASW class (layers 7-10), which contribute $24 \%-25 \%$ of the ACC volume transport. Layers 5-6, comprising the least dense AAIW/AASW fraction and the bulk of SAMW (which represent $12 \%$ of the ACC volume transport), cool by $0.26^{\circ} \mathrm{C}$ and freshen by $0.02-0.03$. Thermohaline changes in layers 1-4, although large, are associated with small volume transports and have a lesser impact on the heat and freshwater fluxes of the ACC. A substantial potential temperature and salinity difference is also apparent in the WSDW layer, linked to the diapycnal mixing with LCDW suggested in section $4 \mathrm{~b}$.

The thermohaline modification of the ACC in the Scotia Sea brings about a net reduction in its heat and salt transports of $0.021 \pm 0.020 \mathrm{PW}$ and $(0.7 \pm 0.6)$ $\times 10^{6} \mathrm{~kg} \mathrm{~s}^{-1}$ [equivalent to an increase in the ACC freshwater transport of $0.020 \pm 0.017 \mathrm{~Sv}$ if it is assumed 


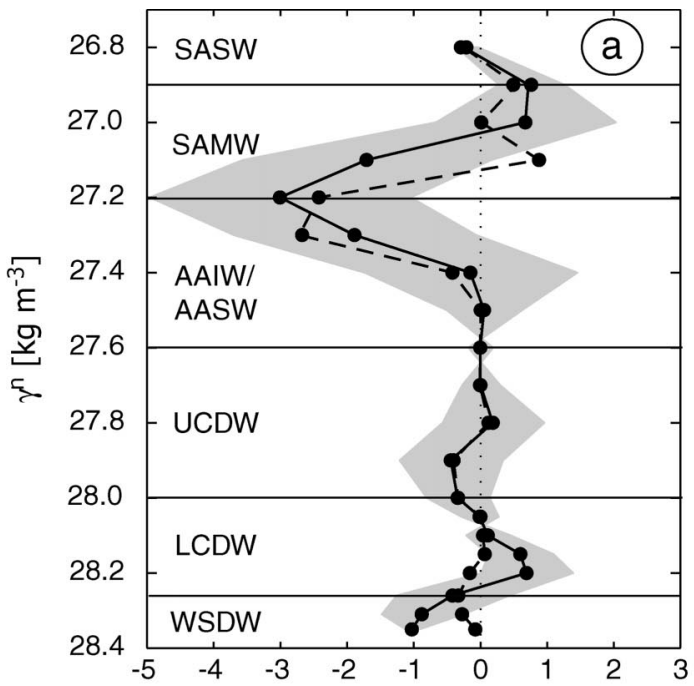

Diapycnal $\theta$ anomaly transport $\left[10^{13} \mathrm{~W}\right]$

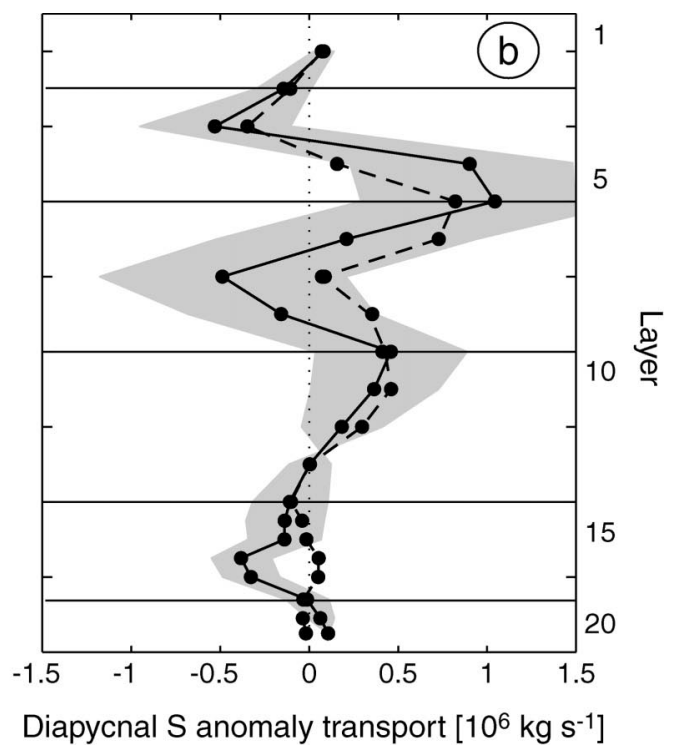

Diapycnal $S$ anomaly transport $\left[10^{6} \mathrm{~kg} \mathrm{~s}^{-1}\right]$

FIG. 9. Interior diapycnal transport (thick solid line) of (a) potential temperature anomaly and (b) salinity anomaly. The dashed line indicates the contribution from the "effective diffusion" term (see section $4 \mathrm{c}$ ), and the shaded area shows the one standard deviation uncertainty. Water masses are labeled, and their boundaries are indicated by horizontal black lines.

that the errors in the volume and salinity equations for each layer are strongly and positively correlated; see Wunsch (1996) for a discussion]. These values correspond to the heat and freshwater flux divergences relative to the volume-transport-weighted mean potential temperature and salinity in each layer (i.e., the influence of layer volume flux divergences has been suppressed). The large uncertainties in these net changes arise from a large cancellation between three principal contributing factors of similar magnitude (Fig. 8b). The cooling and freshening of the CDW in layers 12-18 accounts for $0.028 \pm 0.007 \mathrm{PW}$ (heat loss) and $(1.0 \pm 0.2) \times 10^{6}$ $\mathrm{kg} \mathrm{s}^{-1}$ (salt loss); the warming and salinification of layers 7-10 is responsible for a gain of heat and salt of $0.031 \pm 0.009$ PW and $(0.8 \pm 0.2) \times 10^{6} \mathrm{~kg} \mathrm{~s}^{-1}$; and the cooling and freshening of layers $5-6$ provides a heat and salt deficit of $0.015 \pm 0.006 \mathrm{PW}$ and $(0.4 \pm 0.2)$ $\times 10^{6} \mathrm{~kg} \mathrm{~s}^{-1}$.

In the solution, the modification to the ACC heat and freshwater fluxes in the Scotia Sea is due to a combination of interior and air-sea-driven diapycnal exchanges.

\section{1) INTERIOR DIAPYCNAL MIXING}

An exchange of heat and freshwater between layers is promoted by the vigorous interior diapycnal mixing that characterizes the basin. Figures $9 a$ and $9 b$ show the interior diapycnal flux of potential temperature anomaly and salinity anomaly. (The anomalies are defined relative to the mean property value along the rim of the model domain; therefore, the contribution of the diapycnal volume flux is included in the potential temper- ature and salinity fluxes.) The diapycnal volume transports induced by mixing between WSDW and LCDW result in a significant heat flux divergence and salt flux convergence across those water masses. The net (scaled) potential temperature anomaly and salinity anomaly fluxes across the LCDW-WSDW interface, however, are small $\left[(-0.4 \pm 0.7) \times 10^{13} \mathrm{~W}\right.$ and $(0 \pm 0.1) \times 10^{6}$ $\mathrm{kg} \mathrm{s}^{-1}$ ] and account for only a minor fraction of the cooling and freshening of the bulk of CDW (Fig. 8b). With some caution dictated by the large uncertainties, this hints at the solution being inconsistent with a dominant role of WSDW in ventilating the deep ACC within the basin, as proposed by Locarnini et al. (1993). Interior diapycnal fluxes of potential temperature anomaly are generally indistinguishable from zero throughout the lighter CDW classes and attain larger magnitudes in the SAMW and AAIW/AASW layers. There, the model suggests that interior diapycnal mixing may contribute importantly to the observed warming of layers 7-8 and the cooling of layer 5 (Fig. 8b). Potentially important (though uncertain) diapycnal fluxes of salinity anomaly are diagnosed in the CDW, AAIW/AASW, and SAMW layers. There are indications of an $O\left(0.5 \times 10^{6} \mathrm{~kg} \mathrm{~s}^{-1}\right)$ salt flux divergence in the CDW layer, a similar convergence in layers 8-9, and a divergence in layers 5-6 that are close in magnitude to the changes in salt flux observed in each of those density classes.

A clear distinction can be drawn between the interior diapycnal fluxes acting on isopycnals above and below $\gamma^{n}=28.0 \mathrm{~kg} \mathrm{~m}^{-3}$, corresponding approximately to the densest density surface that outcrops into the surface mixed layer within the model domain. As pointed out 

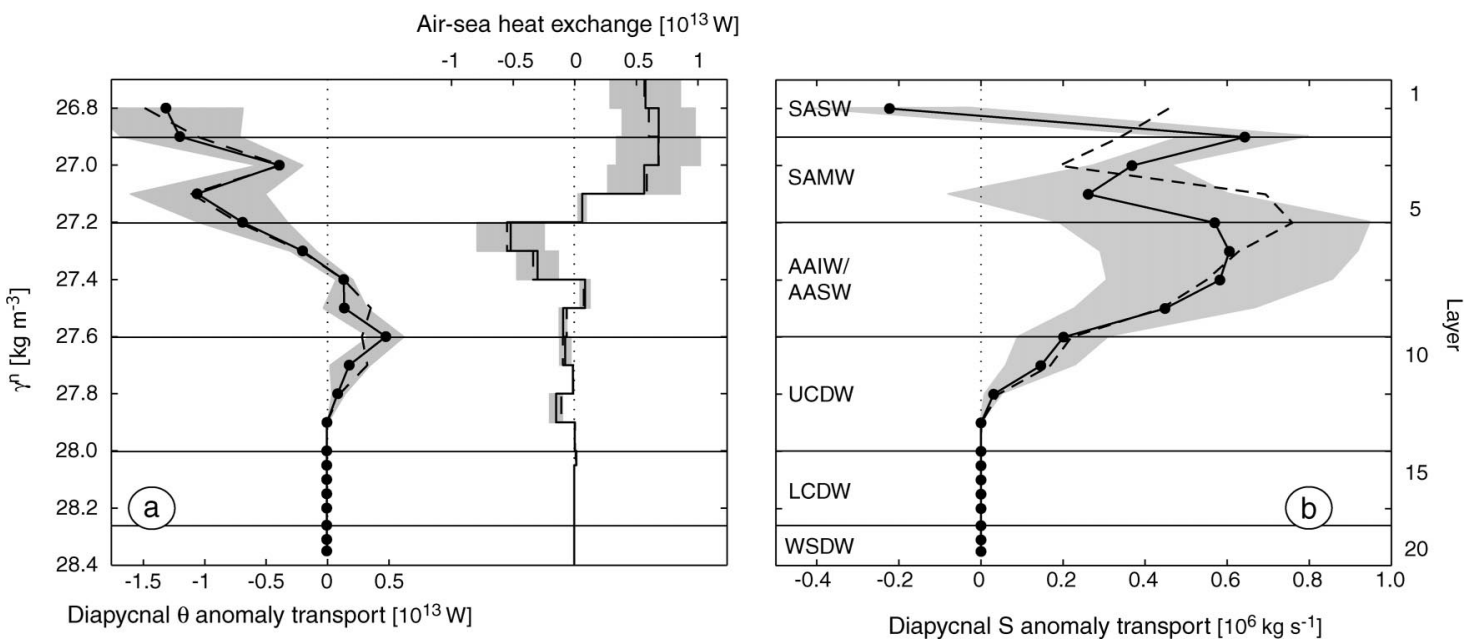

FIG. 10. (a) Surface diapycnal transport of potential temperature anomaly (thick solid line, left) and net air-sea heat exchange (thick solid line, right), and (b) surface diapycnal transport of salinity anomaly (thick solid line). The shaded area gives the one standard deviation uncertainty, and the dashed lines show the initial estimates from HASO and the SOC climatology (see section 2b). Water masses are labeled, and their boundaries are indicated by horizontal black lines.

by Sloyan and Rintoul (2000), the net interior diapycnal potential temperature (or salinity) flux $\left(w_{\theta}^{*} \times \bar{\theta}^{A} \times A\right)$ can be decomposed into a component driven by diapycnal volume advection $\left(w_{V}^{*} \times \bar{\theta}^{A} \times A\right)$ and an "effective diffusion" term $\left(w_{\theta}^{*} \times \bar{\theta}^{A} \times A-w_{V}^{*} \times \bar{\theta}^{A} \times\right.$ $A)$ encompassing all other processes. This second term includes heat transports associated with correlations between spatial variations in potential temperature and the diapycnal volume velocity, as well as a truly diffusive diapycnal transport. In the solution (Figs. 9a,b), diapycnal volume advection dominates over effective diffusion throughout the $\gamma^{n}>28.0 \mathrm{~kg} \mathrm{~m}^{-3}$ density range (layers 15-21), with a generally reverse scenario at and above that isopycnal. Thus, to a great extent, the diapycnal fluxes of heat and freshwater across the UCDW, AAIW/AASW, and SAMW layers in the Scotia Sea are driven by upper-ocean mixing processes that decouple the diapycnal property transports from the areally averaged property values on isopycnals (determined mainly over the region in which the isopycnal lies below the surface mixed layer). Tandon (2001) provides a detailed review of the processes likely contributing to the effective diffusion term (mixed layer entrainment, vertical motions near fronts, eddy-induced horizontal mixing) and proposes a parameterization of the individual terms. Significantly, the model layers at which effective diffusion is dominant lie outside the range (the LCDW and WSDW classes) of increased interior diapycnal volume fluxes linked to the high topographic roughness of the region. This suggests the existence of two distinct regimes of interior diapycnal mixing in the Scotia Sea, supported by disparate physical processes drawing on different energy sources.

\section{2) AIR-SEA-DRIVEN DIAPYCNAL MIXING}

A second agent in driving diapycnal fluxes of heat and freshwater across isopycnals lighter than $\gamma^{n}=28.0$ $\mathrm{kg} \mathrm{m}^{-3}$ is air-sea interaction at surface outcrops. In the southern Scotia Sea, the northward Ekman transport of relatively cold water induces a potential temperature anomaly flux directed to higher densities across layers 8-12 (Fig. 10a, left). This leads to a heat flux convergence of $(0.4 \pm 0.1) \times 10^{13} \mathrm{~W}$ in layers $10-11$, representing the core of UCDW that outcrops near the SB. The combination of northward Ekman transport of cold water (Fig. 10a, left) and winter cooling in the northern Scotia Sea (Fig. 10a, right) causes the upper part of AAIW/AASW (layers 6-7) to lose $(1.7 \pm 0.6) \times 10^{13}$ W. In layer 7, this heat loss is overridden by a larger interior diapycnal heat flux convergence (Fig. 9a). The SAMW class (layers $3-5)$ gains $(0.5 \pm 0.8) \times 10^{13} \mathrm{~W}$ by virtue of summer warming in the northern Scotia Sea counteracting the southward Ekman heat transport, but again this heat gain is small in comparison with the cooling induced in SAMW by the interior diapycnal flux. The surface diapycnal salt anomaly flux (Fig. 10b) is directed toward high densities throughout the model domain (with the exception of layer 1), a result of the northward Ekman transport of relatively fresh water. There is a salt flux convergence of $(0.6 \pm 0.3) \times 10^{6}$ $\mathrm{kg} \mathrm{s}^{-1}$ across the UCDW and AAIW/AASW layers that appears to be the main cause of the salinification of layers 7-10 (Fig. 7) and a divergence of $(0.3 \pm 0.3) \times$ $10^{6} \mathrm{~kg} \mathrm{~s}^{-1}$ in the lower fraction of SAMW that contributes significantly to the freshening of layer 5 .

\section{3) WHICH IS THE DOMINANT MIXING PROCESS?}

We have shown that the cooling and freshening of the bulk of SAMW (layer 5) and the uppermost layer of AAIW/AASW (layer 6) as the ACC crosses the Scotia Sea is mainly promoted by a divergence of the interior diapycnal fluxes of heat and salt. Similarly, the primary 
cause of the warming of much of AAIW/AASW (layers 7-9) and uppermost layer of UCDW (layer 10) is a convergence of the interior diapycnal heat flux. The salinification of layers $7-10$ is due to a convergence of the surface and interior diapycnal salt fluxes. In contrast, there is no diapycnal mixing process in the solution capable of providing the heat and salt flux divergence required to explain the cooling and freshening of the bulk of CDW. The implication is that the heat lost (freshwater gained) by the CDW class in the ACC must be exported to (imported from) the Weddell gyre through isopycnal stirring. Thus, in the solution, $(2.5 \pm 0.7) \times$ $10^{13} \mathrm{~W}$ of heat and $(0.6 \pm 0.3) \times 10^{6} \mathrm{~kg} \mathrm{~s}^{-1}$ of salt are seen to be transported southward across the SB along layers 12-18 [cf. diapycnal heat and salt flux divergences in those layers of $(0.5 \pm 1.1) \times 10^{13} \mathrm{~W}$ and $(0.2$ $\left.\pm 0.3) \mathrm{kg} \mathrm{s}^{-1}\right]$. This is consistent with the mechanism proposed by Whitworth et al. (1994), which emphasizes the role of the Weddell-Scotia Confluence in ventilating the deep ACC along isopycnals.

\section{d. Cross-ACC heat and freshwater transport and overturning circulation}

The southward heat export across the ACC, and ultimately across its $\mathrm{SB}$, is a crucial component of the meridional overturning of the Southern Ocean, as it supplies the oceanic heat loss that is the main driving force of deep ventilation (and, in particular, AABW formation) south of the current. In the solution, a significant southward isopycnal heat export of $0.025 \pm 0.007 \mathrm{PW}$ (within layers 12-18, which conserve mass in the ACC to a good approximation) across the SB (Fig. 8b) is implied that drives the observed cooling of the deep ACC in the Scotia Sea (Fig. 8a). It is accompanied by a northward isopycnal freshwater import of $0.02 \pm 0.01$ $\mathrm{Sv}$ across the SB, responsible for the freshening of the deep ACC. The inferred heat flux is approximately half of the net heat transfer from the latitude band of the ACC to the Weddell gyre sector west of the Prime Meridian, quantified as $0.05 \pm 0.01 \mathrm{PW}$ across the AJAX section by Sloyan and Rintoul (2001). In our model domain, a heat export rate per unit distance of $0.9 \times$ $10^{10} \mathrm{~W} \mathrm{~km}^{-1}$ can be estimated by normalizing the calculated heat export by the distance along the climatological SB of Orsi et al. (1995) within the domain (2758 $\mathrm{km})$. If this rate were representative of the mean value along the circumpolar path of the SB (22 $367 \mathrm{~km})$, the total southward heat export across the southern edge of the ACC would be $0.21 \mathrm{PW}$, within the range of previous estimates of cross-ACC heat flux (0.2-0.65 PW; see section 1). This consistency argues for the abrupt cooling of the ACC in the Scotia Sea not being exclusively attributable to a large heat export across the SB in the basin, which could be promoted by the regional confluence of the ACC and the Weddell gyre. An additional cause for the cooling may be the absence of a heat influx from the north within the Scotia Sea, a basin unique in

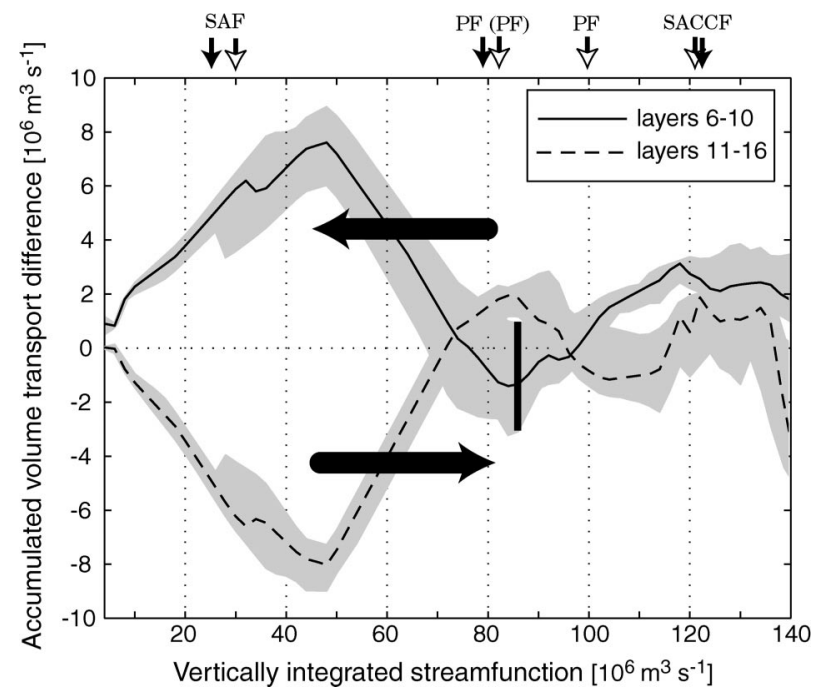

FIG. 11. Accumulated difference in ACC volume transport (outflow - inflow) in two layer groups, plotted against the full-depth volume transport of the ACC. The shaded area gives the one standard deviation uncertainty. The thick arrows indicate the direction of crossstream translation suggested by the volume transport difference curves. The thick solid line indicates the streamfunction value at which layer 6 crosses the 150-m depth level, which typically represents the depth of the winter mixed layer in the ACC. Layers 610 span the AAIW class and uppermost fraction of UCDW, whereas layers 11-16 include the bulk of UCDW and LCDW. The locations of the ACC fronts at Drake Passage (solid arrows) and the outflow region (open arrows) are indicated in the upper axis.

the Southern Ocean in that the SAF hugs the continental slope (Orsi et al. (1995), effectively isolating the ACC from the subtropical ocean circulation. This view finds support in the work of Arhan et al. (2002), who showed that the only input of subtropical water to the model domain (a highly diluted component of NADW from the Argentine Basin flowing south over the eastern part of the Falkland Plateau; see Figs. 2 and 4), conveys a negligibly small heat and salt flux. The Scotia Sea region thus offers a rare opportunity to examine the overturning circulation (and associated heat and freshwater fluxes) across the ACC in the absence of significant exchanges with the subtropical ocean. This represents a notable advantage over the situation encountered by Gille (1999) in her inverse model of the ACC in the southeast Pacific. The resolution of her model was insufficient to detect alongstream imbalances between the heat input into the ACC across its northern edge and the heat exported across its southern edge and to the atmosphere.

The northward transfer of approximately $5 \mathrm{~Sv}$ of WSDW from the Weddell gyre to the ACC (Fig. 4, lower panel) and the northward air-sea-driven diapycnal transport of 1-3 Sv of near-surface water (Fig. 7) are the most obvious (but not the sole) manifestations of a cross-ACC meridional overturning in the Scotia Sea. This is demonstrated in Fig. 11, showing the accumulated volume transport difference (outflow minus inflow) in intermediate and deep layers of the ACC as a 
function of the full-depth integrated streamfunction. There is a significant overturning-like circulation of 8 $\pm 1 \mathrm{~Sv}$ along isopycnals across the polar frontal zone, the hydrographic region between the SAF and PF that represents the core of the ACC. The overturning consists of a poleward transport across streamlines in layers 1116 (which encompass the bulk of the UCDW and LCDW layers, at depths of 800-3700 m) compensated by an equatorward transport of the same magnitude in layers 6-10 (including the AAIW/AASW class and the uppermost fraction of UCDW, in the 200-1300-m depth range). This density distribution is in good agreement with that estimated by Gille (1999) near the northern edge of the ACC in the southeast Pacific, the conceptual model of the cross-ACC overturning circulation of Bryden and Cunningham (2003), and the diagnostics of Ganachaud and Wunsch (2000) at $30^{\circ} \mathrm{S}$ (see section 1). In contrast, there is an apparent disagreement with the density distribution of the net overturning across $30^{\circ}-$ $40^{\circ} \mathrm{S}$ inferred by Sloyan and Rintoul (2001), although their results for the individual ocean basins suggest that the discordance could be attributable to regional variability in the structure of the overturning.

The lower limb of the overturning is likely to be at least partially driven by interaction with the North Scotia Ridge (Fig. 1), which to the west of Shag Rocks Passage has a sill depth close to $1500 \mathrm{~m}$. CDW near the SAF at Drake Passage may conceivably decouple from the frontal jet and follow the southern flank of the ridge as a deep boundary current as far as the PF, which overflows the ridge at Shag Rocks Passage. In contrast, the layers involved in the upper limb of the overturning (and possibly UCDW in the lower limb) lie above bathymetric obstacles, and their cross-stream flow may be forced by eddy stirring. Satellite altimetric data (e.g., Hughes and Ash 2001) reveal that the northwestern Scotia Sea is indeed one of the regions of highest eddy kinetic energy along the ACC core, with eddies propagating downstream along a band corresponding closely with the polar frontal zone. This interpretation of the inferred cross-stream circulation is consistent with the meridional overturning paradigms of Speer et al. (2000) and Bryden and Cunningham (2003) (among other contemporary studies), although the former authors use a definition of the southward-flowing UCDW that partially overlaps with the density class of northward-flowing AAIW/AASW in this study.

The overturning across full-depth streamlines drives a cross-stream poleward transport of heat and salt (equivalent to an equatorward freshwater flux), as evidenced in Fig. 12. Northern ACC waters (equatorward of the 70-Sv streamline) are significantly colder and fresher in the outflow region than at Drake Passage, and southern ACC waters are warmer and more saline. (The cooling and freshening of layers $9-18$ in the region south of the $110-\mathrm{Sv}$ streamline, close to the SACCF, is the signature of the isopycnal heat export to, and freshwater import from, the Weddell gyre.) The signal is concentrated in layers with appreciable isopycnal potential temperature and salinity gradients across streamlines (layers 2-11). Integrating the product of the layer cross-streamline volume transport (as in Fig. 11) and the layer potential temperature or salinity difference (as in Fig. 12) between layers 6 and 16 yields a poleward flux of $0.022 \pm 0.010 \mathrm{PW}$ of heat and $(0.6 \pm 0.3) \times$ $10^{6} \mathrm{~kg} \mathrm{~s}^{-1}$ of salt (or $0.02 \pm 0.01 \mathrm{~Sv}$ of freshwater, under the assumption indicated in section $4 \mathrm{c}$ ) across the ACC core. If these heat and freshwater fluxes are normalized by the distance along the climatological PF of Orsi et al. (1995) in the model domain $(2571 \mathrm{~km})$ and then scaled by the circumpolar PF length $(27181 \mathrm{~km})$, a total poleward heat flux of $0.23 \pm 0.10 \mathrm{PW}$ and an equatorward freshwater flux of $0.2 \pm 0.1 \mathrm{~Sv}$ across the ACC core are obtained. An analogous extrapolation based on the SAF suggests substantially larger heat and freshwater fluxes of $0.40 \pm 0.16 \mathrm{PW}$ and $0.4 \pm 0.2 \mathrm{~Sv}$. Both heat flux values fall within the range of previous estimates for the net cross-ACC poleward heat flux. However, the same is not true of a circumpolar extrapolation of the observed volume overturning rate, which would yield an overturning of 75-160 Sv, considerably larger than suggested by basin-scale analyses. This may indicate that the volume overturning in the Scotia Sea is exceptionally large (possibly due to the high eddy kinetic energy levels in the region) and inefficient in transferring heat across the current. Such inefficiency would be fostered by the effective isolation of the basin from the subtropical gyres, which results in a low meridional isopycnal potential temperature gradient across the ACC core (e.g., Olbers et al. 1992, their Plate 38).

The magnitude and density distribution of the poleward heat flux diagnosed in this study are in reasonable agreement with profiles of the eddy heat flux obtained with moored current meter arrays in northern Drake Passage (Nowlin et al. 1985) and two sites south of Australasia (Bryden and Heath 1985; Phillips and Rintoul 2000); see Gille (2003) for a review of all mooringbased heat flux determinations in the Southern Ocean. This reinforces our suggestion that the isopycnal component of the overturning circulation is largely driven by mesoscale eddies. To make our model diagnostics comparable with the point heat flux measurements of current meters, the poleward heat flux in each model layer was scaled by the mean layer thickness in the polar frontal zone and the distance along polar frontal zone streamlines in the model domain (exemplified by the climatological SAF and PF). A roughly exponential profile was obtained (Fig. 13), with peak heat fluxes of 20$40 \mathrm{~kW} \mathrm{~m}^{-2}$ in layers 6-7 decreasing rapidly with density to a value of $3-5 \mathrm{~kW} \mathrm{~m}^{-2}$ in layer 10 . In comparison, current meter records typically show heat fluxes of 20$110 \mathrm{~kW} \mathrm{~m}^{-2}$ around 500-m depth diminishing to less than $10 \mathrm{~kW} \mathrm{~m}^{-2}$ below $1000 \mathrm{~m}$. Gille (2003) estimated a mean poleward eddy heat flux across the ACC core of about $4-10 \mathrm{~kW} \mathrm{~m}^{-2}$ at $900 \mathrm{~m}$ from ALACE float data, and showed that the Scotia Sea hosts a higher- 


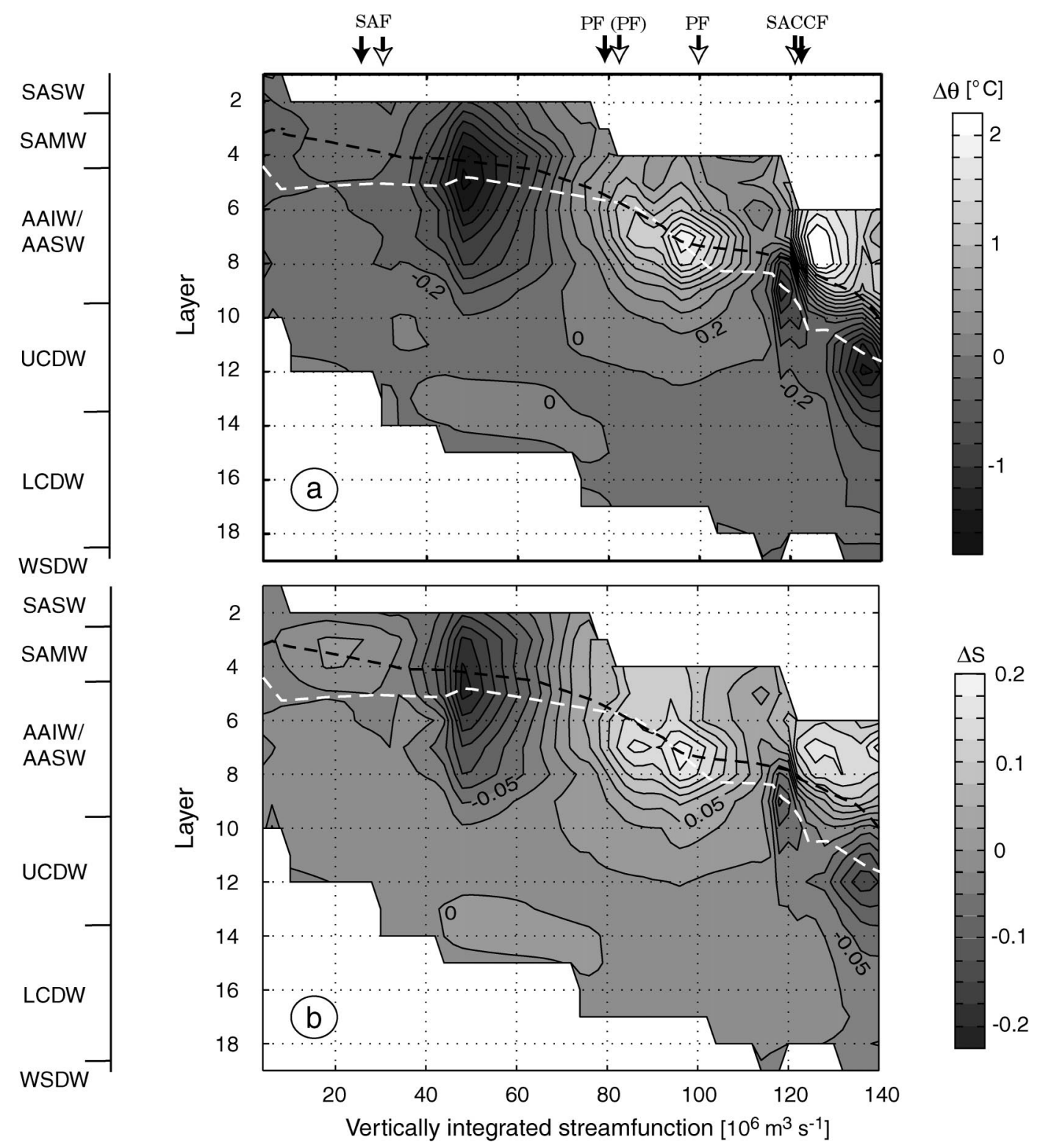

FIG. 12. Along-streamline difference (outflow - inflow) in ACC layer-mean (a) potential temperature and (b) salinity. The pattern is robust, and the uncertainty in the magnitude of the difference is approximately $30 \%$. The locations of the ACC fronts at Drake Passage (solid arrows) and the outflow region (open arrows) are indicated in the upper axis. The dashed lines mark the 150-m depth level at Drake Passage (white) and the outflow region (black).

than-average heat flux of $25-50 \mathrm{~kW} \mathrm{~m}^{-2}$, consistent with values in layers $6-8$ in the solution.

The compatibility between the heat flux diagnostics in this study and those from current meters and floats is extendable to their dynamical implications. It has been suggested (e.g., Bryden and Cunningham 2003) that interfacial form stress may transfer the momentum input by wind stress at the ocean surface vertically to the ocean floor where it is dissipated by topographic form stress. This leads to the following relationship between the wind stress and the eddy heat flux:

$$
\tau^{x} \approx \rho_{0} f \frac{\overline{v^{\prime} \theta^{\prime}}}{\theta_{z}},
$$

where $\rho_{0}$ is a reference potential density, $v^{\prime}$ and $\theta^{\prime}$ are cross-stream velocity and the perturbation to the timemean potential temperature on a streamline, the overbar represents a temporal or spatial average, $\theta_{z}$ is the vertical gradient of potential temperature, and $\tau^{x}$ is the alongstream wind stress. Scaling the diagnosed heat fluxes by the layer-mean vertical potential temperature gradient in the polar frontal zone yields an interfacial form 


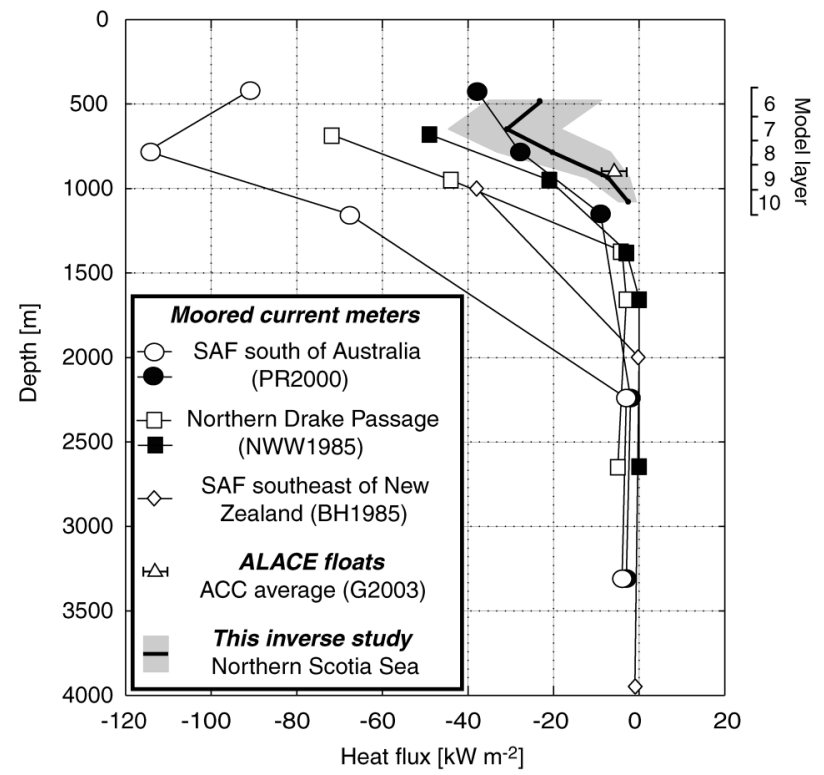

FIG. 13. Representative profiles of cross-stream eddy heat flux measured near the ACC core (figure adapted from Phillips and Rintoul 2000). Open symbols refer to calculations considering all frequencies, and filled symbols refer to those considering the eddy band (defined as having a maximum period of 90 days) only. The following citations are abbreviated: Phillips and Rintoul (2000) (PR2000); Nowlin et al. (1985) (NWW1985); Bryden and Heath (1985) (BH1985); Gille (2003, G2003). Point cross-stream heat fluxes (and error bars) corresponding to this inverse study were calculated by scaling the crossstream heat flux in each layer by the mean layer thickness in the polar frontal zone and the distance along streamlines within the model domain (estimated as 1500-2000 km).

stress of $0.09-0.2 \mathrm{~N} \mathrm{~m}^{-2}$ in layers $6-10$, which is close to values derived from current meter and float data and appears to be sufficient to balance the $\sim 0.1 \mathrm{~N} \mathrm{~m}^{-2}$ input at the surface by the wind (Gille et al. 2001).

\section{Conclusions}

In this study, we have used full-depth hydrographic, tracer, and velocity data collected along the rim of the Scotia Sea during the ALBATROSS cruise in combination with climatological hydrographic, wind stress, and air-sea heat and freshwater flux data to construct an inverse box model of the ACC in the region. The model is formulated in terms of isopycnal layers and provides concurrent estimates (with error bars) of geostrophic and wind-driven Ekman transports across the boundaries of the domain, air-sea-driven diapycnal fluxes and net air-sea heat exchanges at surface outcrops of isopycnals, and "interior" diapycnal fluxes below the ocean surface.

The volume transport field diagnosed by the model is summarized in Fig. 14. The full-depth ACC volume transport through Drake Passage is $143 \pm 13 \mathrm{~Sv}$ eastward, increasing to $149 \pm 16 \mathrm{~Sv}$ in the outflow region to the north and east. The prime cause of this increase is the incorporation into the ACC of the bulk of the 5.9 $\pm 1.7 \mathrm{~Sv}$ of WSDW that overflow the South Scotia Ridge as the Weddell gyre penetrates the Scotia Sea. The volume transport of the ACC is redistributed both laterally between frontal zones and vertically between different density classes in crossing the region. The fulldepth transport associated with the SAF increases noticeably (from $31 \pm 7$ to $48 \pm 4 \mathrm{~Sv}$ ) and there is a topographically induced branching of the $70-80 \mathrm{~Sv} \mathrm{PF}$ jet that transfers an additional 14-37 Sv of PF water to the Falkland Current. This current in turn transports 63$86 \pm 6 \mathrm{~Sv}$ toward the subtropical gyre. The ACC undergoes a general densification in the Scotia Sea, with increased volume transport in the WSDW layer $(+5 \mathrm{~Sv})$, the denser fraction of LCDW (+2 Sv) and the AAIW/ AASW class $(+2 \mathrm{~Sv})$, and decreased transport of SAMW $(-2 \mathrm{~Sv})$.

In parallel with changes to the volume transport the heat and freshwater fluxes associated with the ACC are profoundly modified in the Scotia Sea, resulting in a net reduction of $0.021 \pm 0.020 \mathrm{PW}$ and a net increase of $0.020 \pm 0.017 \mathrm{~Sv}$, respectively. These modifications are brought about by the combined cooling (by $0.08^{\circ}-$ $0.13^{\circ} \mathrm{C}$ ) and freshening (by $0.009-0.026$ ) of the entire CDW layer denser than $\gamma^{n}=27.80 \mathrm{~kg} \mathrm{~m}^{-3}$, which accounts for nearly one-half of the ACC volume transport; the warming (by $0.10^{\circ}-0.26^{\circ} \mathrm{C}$ ) and salinification (by $0.005-0.027$ ) of the AAIW/AASW class and upper fraction of UCDW; and the cooling (by $0.26^{\circ} \mathrm{C}$ ) and freshening (by 0.02-0.03) of SAMW and lightest AAIW/AASW layer.

Our results indicate that the mixing processes driving the modifications to the ACC layer mass, heat, and freshwater transports in the Scotia Sea are of a distinct nature for layers above and below the UCDW-LCDW boundary (Fig. 15). Intense, topographically induced interior diapycnal mixing is suggested between the WSDW and LCDW layers, spanning a density class that extends up to 1500-2000 $\mathrm{m}$ above the ocean floor over much of the region. This leads to a substantial vertical redistribution of volume and properties within each water mass, with relatively little net transfer between the two. The drastic cooling and freshening of CDW denser than $\gamma^{n}=27.80 \mathrm{~kg} \mathrm{~m}^{-3}$ in the Scotia Sea is effected principally through isopycnal exchanges with waters in the northern Weddell gyre, as conjectured by Whitworth et al. (1994). A different mixing regime is apparent in the lighter UCDW class and the AAIW/AASW and SAMW layers. In this regime, "interior" diapycnal transfers are dominated by mixing in the upper ocean (effective diffusion), and air-sea-driven diapycnal fluxes at surface outcrops are important. Most notably, the surplus of AAIW/AASW in the outflowing ACC is due to a convergence of the diapycnal Ekman transport of denser water and an uncertain interior conversion of SAMW to AAIW/AASW. This conversion combines with an air-sea-driven diapycnal volume flux divergence in the SAMW class to induce a consumption of that water mass in the region. The diapycnal thermo- 


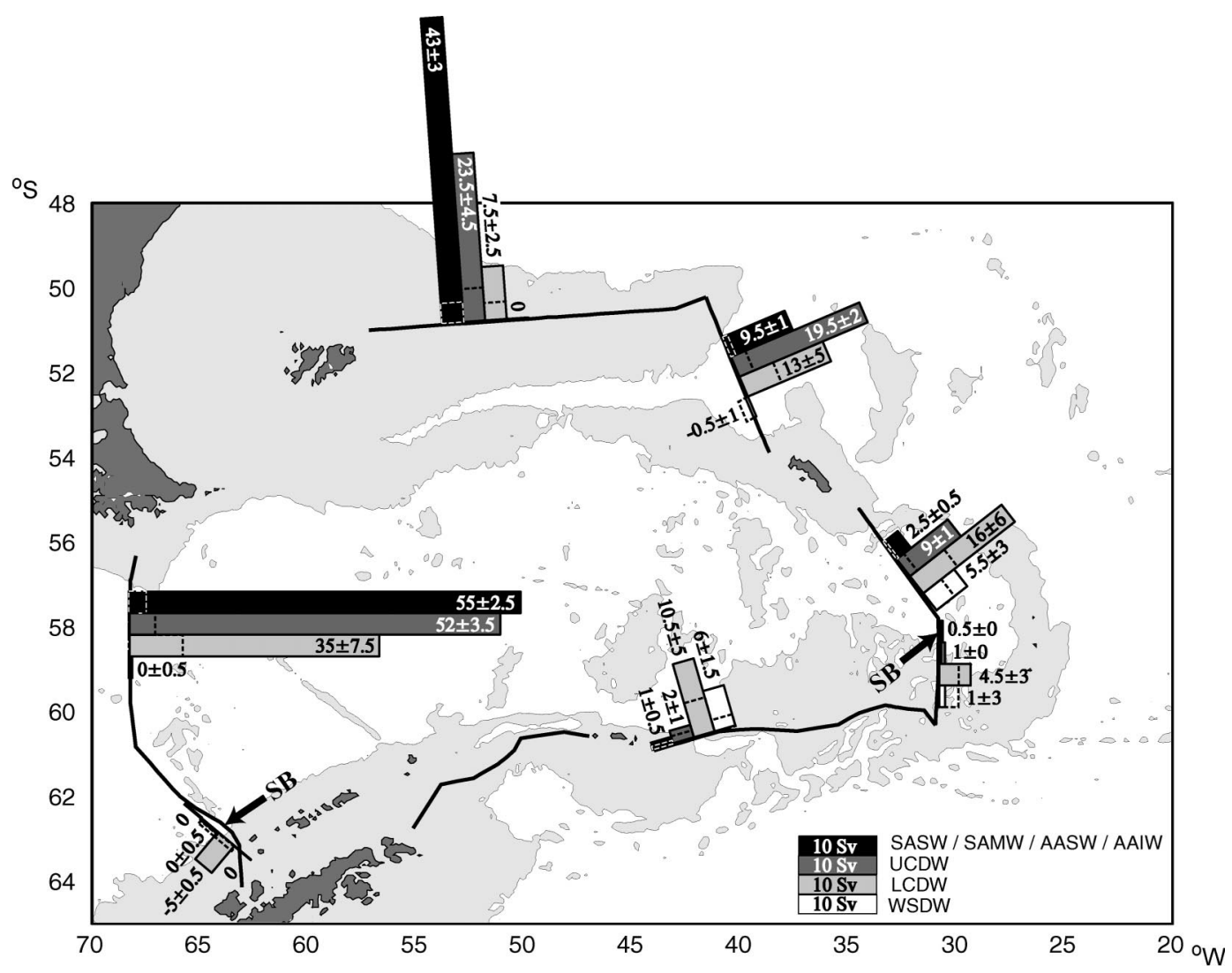

FIG. 14. Synthesis of the (geostrophic + Ekman) volume transport field diagnosed by the model, superimposed on the bathymetry of the Scotia Sea. The region shallower than $3000 \mathrm{~m}$ is shaded light gray. The ALBATROSS cruise track is indicated by the thick solid line, and the crossings of the SB are marked by the black arrows. Volume transports are calculated and plotted separately for seven zones: the ACC at Drake Passage, the region south of the SB at Drake Passage, the transect along the South Scotia Ridge, the Weddell-Scotia Confluence in the eastern Scotia Sea, the ACC sector south of South Georgia, the section across the western Georgia Basin, and the transect along the Falkland Plateau. Transports are given in four density classes: surface and intermediate waters (layers 1-9), UCDW (layers 10-13), LCDW (layers 14-18), and WSDW (layers 19-21). Bar labels represent transport values (Sv), and the scale of the bars is provided in the lower-right-hand corner of the figure. Dashed bars indicate one standard deviation error bars.

haline modification of the SAMW and AAIW/AASW layers is primarily driven by upper-ocean mixing processes.

Superimposed on this pattern of diapycnal exchanges between layers, a cross-stream overturning circulation of $8 \pm 1 \mathrm{~Sv}$ along isopycnals is diagnosed by the model in the ACC core (Fig. 15). The lower, poleward limb of the overturning encompasses the bulk of the CDW $\left(\gamma^{n}>27.7 \mathrm{~kg} \mathrm{~m}^{-3}\right)$ and may be partially driven by interaction with the North Scotia Ridge. The upper, equatorward limb spans the lightest fraction of UCDW, AAIW, and possibly lighter waters that are shallower than any topographic obstacles encountered by the ACC in the basin. The signature of the overturning is clearest in the polar frontal zone, a region of very high eddy kinetic energy, suggesting that mesoscale eddies may be the primary driving agent of the overturning. The density distribution of the overturning is broadly consistent with that inferred at subtropical latitudes by other works (e.g., Ganachaud and Wunsch 2000) and present conceptual models of the cross-ACC overturning circulation (e.g., Bryden and Cunningham 2003). Comparison with these studies suggests, however, that the intensity of the overturning in the Scotia Sea may be higher than the circumpolar average.

The occurrence of significant isopycnal potential temperature and salinity gradients in the upper limb results in the overturning inducing a poleward heat flux of $0.022 \pm 0.009 \mathrm{PW}$ and an equatorward freshwater flux of $0.02 \pm 0.01 \mathrm{~Sv}$ across the ACC core. These isopycnal fluxes may account for much of the observed cooling and freshening of SAMW and AAIW as the northern ACC crosses the Scotia Sea (Piola and Gordon 1989). Adequately scaled, the heat flux value compares favorably with estimates of the total cross-ACC heat flux (0.2-0.65 PW) inferred from heat budget studies of the polar ocean (e.g., Gordon and Owens 1987). Good agreement is also found with point estimates from current meters at a range of depths and geographical locations (Phillips and Rintoul 2000) and with estimates 


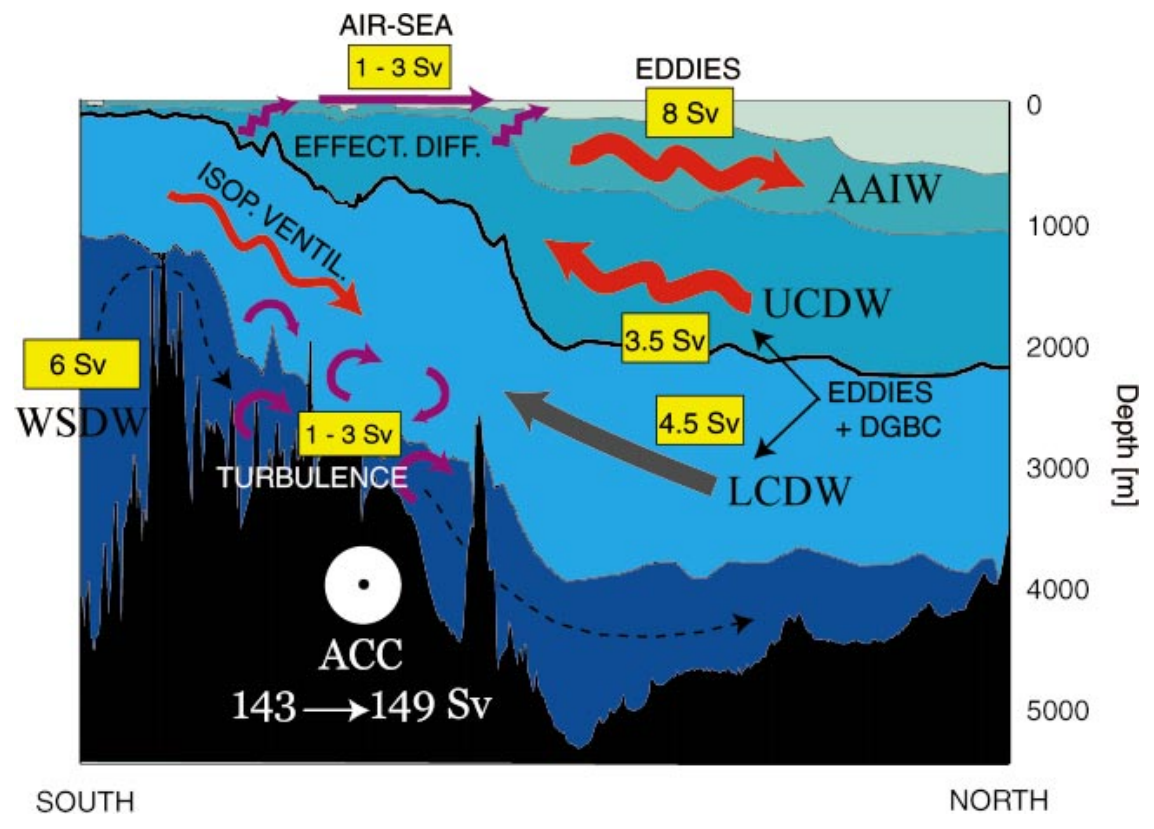

FIG. 15. Schematic synthesis of the elements of the cross-ACC overturning circulation in the Scotia Sea region, as diagnosed by the inverse model. The $6 \mathrm{~Sv}$ increase in ACC transport is fed by an import of $6 \mathrm{~Sv}$ of WSDW over the South Scotia Ridge. High turbulent diapycnal mixing rates, inducing diapycnal volume fluxes of $1-3 \mathrm{~Sv}$, are found in the LCDW and WSDW layers in connection with the rough topography of the region. The large cooling and freshening undergone by the CDW in the ACC in crossing the basin is driven primarily by isopycnal exchanges with the northern Weddell gyre. There is an overturning-like circulation of about $8 \mathrm{~Sv}$ in which CDW flows southward and intermediate water (including the lightest fraction of UCDW) flows northward across ACC streamlines. This circulation is likely driven by a combination of eddies and deep geostrophic boundary currents (DGBC) and has an associated poleward heat flux and an equatorward freshwater flux. Air-sea exchanges of heat, freshwater and momentum in the ACC induce northward diapycnal volume fluxes of 1-3 Sv across the current. Diapycnal exchanges of heat and freshwater in outcropping layers are controlled by upper-ocean mixing processes (effective diffusion).

at $900 \mathrm{~m}$ derived from ALACE float measurements in the region (Gille 2003).

Acknowledgments. The ALBATROSS cruise was funded by the Natural Environment Research Council Grant GR3/11654. We are grateful to Elaine McDonagh for insightful discussions of inverse techniques and to Brian King and Stuart Cunningham for permitting the use of nonpublic WOCE SR1b section data in this study. Harry Bryden and two anonymous reviewers provided useful comments on an earlier version of the manuscript. We thank Bernadette Sloyan and Alexandre Ganachaud for making their doctoral theses available and Steve Rintoul for providing the DOBOX software. Simon Josey's assistance with the SOC climatology is gratefully acknowledged.

\section{APPENDIX}

\section{Formulation of Air-Sea Exchanges of Mass, Heat, and Salt}

The model's formulation of air-sea interaction is a slightly modified version of that of Sloyan and Rintoul
(2001), itself based on Speer and Tziperman (1992). We distinguish between direct contributions (net mass and heat exchanges between outcropping layers and the atmosphere) and indirect contributions (net fluxes of mass, heat, and salt across outcropping layer interfaces elicited by air-sea interaction). For a given layer, the former can be calculated by integrating the sea-air freshwater flux $(Q)$ and air-sea heat flux $(H)$, which are a function of position and time, over the outcropping area of the layer ( $A$, a function of time) and an annual cycle (indicated by $T$ ):

$$
\begin{aligned}
& M_{V}=\int_{T} d t \int_{A}-Q d A, \\
& M_{\theta}=\int_{T} d t \int_{A} \frac{H}{C_{p} \rho} d A,
\end{aligned}
$$

where $\rho$ is potential density, $C_{p}$ is specific heat capacity, and the mass (heat) exchange has been expressed as a volume (potential temperature) exchange $M_{V}\left(M_{\theta}\right)$. In our model, $M_{V}$ is far smaller than uncertainties in mass conservation introduced by baroclinic variability and is therefore neglected. 
Diapycnal fluxes of volume $\left(F_{V}\right)$, potential temperature $\left(F_{\theta}\right)$, and salinity $\left(F_{S}\right)$ elicited by air-sea interaction across an outcropping layer interface of potential density $\rho$ can be calculated as

$$
F_{V}(\rho)=\int_{T} d t\left\{E(\rho)+\int_{A_{\Delta}} d A\left[\frac{1}{\Delta \rho}\left(\frac{-\alpha H}{C_{p}}+\rho \beta Q S\right)\right]\right\},
$$

$F_{\theta}(\rho)=\int_{T} d t\left[E(\rho) \bar{\theta}^{\mathrm{Ek}}(\rho)\right], \quad$ and

$F_{S}(\rho)=\int_{T} d t\left[E(\rho) \bar{S}^{\mathrm{Ek}}(\rho)\right]$,

where $E(\rho)$ is the wind-driven Ekman transport across the interface, $\Delta \rho$ is a potential density interval centered at $\rho, A_{\Delta}$ is the outcropping area of that density interval, $\alpha$ and $\beta$ are the thermal expansion and haline contraction coefficients, respectively, and $\bar{\theta}^{\mathrm{Ek}}(\rho)$ and $\bar{S}^{\mathrm{Ek}}(\rho)$ are the weighted-mean potential temperature and salinity over the Ekman layer at the outcrop of the layer interface.

Expressions (A1)-(A4) have been used to estimate $M_{\theta}, F_{V}, F_{\theta}$, and $F_{S}$ from climatological data as explained in section $2 b$.

\section{REFERENCES}

Arhan, M., A. C. Naveira Garabato, K. J. Heywood, and D. P. Stevens, 2002: The Antarctic Circumpolar Current between the Falkland Islands and South Georgia. J. Phys. Oceanogr., 32, 1914-1931.

Beckmann, A., H. H. Hellmer, and R. Timmermann, 1999: A numerical model of the Weddell Sea: Large-scale circulation and water mass distribution. J. Geophys. Res., 104, 23 375-23 391.

Broecker, W., and Coauthors, 1998: How much deep water is formed in the Southern Ocean? J. Geophys. Res., 103, 15 833-15 843.

Bryden, H. L., and R. D. Pillsbury, 1977: Variability of deep flow in Drake Passage from year-long current measurements. J. Phys. Oceanogr., 7, 803-810.

—_, and R. A. Heath, 1985: Energetic eddies at the northern edge of the Antarctic Circumpolar Current. Progress in Oceanography, Vol. 14, Pergamon, 65-87.

, and S. A. Cunningham, 2003: How wind-forcing and air-sea heat exchange determine the meridional temperature gradient and stratification for the Antarctic Circumpolar Current. J. Geophys. Res., 108, 3275, doi:10.1029/2001JC001296.

Cunningham, S. A., S. G. Alderson, B. A. King, and M. A. Brandon, 2003: Transport and variability of the Antarctic Circumpolar Current in Drake Passage. J. Geophys. Res., 108, 8084, doi: 10.1029/2001JC001147.

deSzoeke, R. A., and M. D. Levine, 1981: The advective flux of heat by mean geostrophic motions in the Southern Ocean. Deep-Sea Res., 28, 1057-1085.

Egbert, G. D., A. F. Bennett, and M. G. Foreman, 1994: TOPEX/ POSEIDON tides estimated using a global inverse model. $J$. Geophys. Res., 99, 24 821-24 852.

Ganachaud, A., 1999: Large scale oceanic circulation and fluxes of freshwater, heat, nutrients and oxygen. Ph.D. thesis, Massachusetts Institute of Technology/Woods Hole Oceanographic Institution Joint Program, $267 \mathrm{pp}$.

, and C. Wunsch, 2000: Improved estimates of global ocean circulation, heat transport and mixing from hydrographic data. Nature, 408, 453-457.
- , and —- 2003: Large-scale ocean heat and freshwater transports during the World Ocean Circulation Experiment. J. Climate, 16, 696-705.

Georgi, D. T., and J. M. Toole, 1982: The Antarctic Circumpolar Current and the oceanic heat and freshwater budgets. J. Mar. Res., 40, 183-197.

Gille, S. T., 1999: Mass, heat, and salt transport in the southeast Pacific: A Circumpolar Current inverse model. J. Geophys. Res., 104, 5191-5209.

, 2003: Float observations in the Southern Ocean. Part II: Eddy fluxes. J. Phys. Oceanogr., 33, 1182-1196.

- D. P. Stevens, R. T. Tokmakian, and K. J. Heywood, 2001: Antarctic Circumpolar Current response to zonally averaged winds. J. Geophys. Res., 106, 2743-2759.

Gordon, A. L., and W. B. Owens, 1987: Polar oceans. Rev. Geophys., 25, 227-233

_- M. Visbeck, and B. Huber, 2001: Export of Weddell Sea Deep and Bottom Water. J. Geophys. Res., 106, 9005-9017.

Gouretski, V., and K. Jancke, 1998: A new World Ocean climatology: Optimal interpolation of historical and WOCE data on neutral surfaces. WOCE Rep. 162/98, Hamburg, Germany.

Heywood, K. J., and D. P. Stevens, 2000: ALBATROSS cruise report. UEA Cruise Report Series No. 6, 61 pp.

— A. C. Naveira Garabato, and D. P. Stevens, 2002: High mixing rates in the abyssal Southern Ocean. Nature, 415, 1011-1014.

Hughes, C. W., and E. R. Ash, 2001: Eddy forcing of the mean flow in the Southern Ocean. J. Geophys. Res., 106, 2713-2722.

Jackett, D., and T. J. McDougall, 1997: A neutral density variable for the world's oceans. J. Phys. Oceanogr., 27, 237-263.

Josey, S. A., E. C. Kent, and P. K. Taylor, 1998: The Southampton Oceanography Centre (SOC) Ocean-Atmosphere Heat, Momentum and Freshwater Flux Atlas. Southampton Oceanography Centre Report, 6, $30 \mathrm{pp}$. and plates.

Karsten, R., H. Jones, and J. Marshall, 2002: The role of eddy transfer in setting the stratification and transport of a Circumpolar Current. J. Phys. Oceanogr., 32, 39-54.

Keffer, T., and G. Holloway, 1988: Estimating Southern Ocean eddy flux of heat and salt from satellite altimetry. Nature, 332, 624626.

Locarnini, R. A., T. Whitworth III, and W. D. Nowlin Jr., 1993: The importance of the Scotia Sea on the outflow of Weddell Sea Deep Water. J. Mar. Res., 51, 135-153.

Macdonald, A. M., 1998: The global ocean circulation: A hydrographic estimate and regional analysis. Progress in Oceanography, Vol. 41, Pergamon, 281-382.

McIntosh, P. C., and S. R. Rintoul, 1997: Do box inverse models work? J. Phys. Oceanogr., 27, 291-308.

Naveira Garabato, A. C., K. J. Heywood, and D. P. Stevens, 2002a: Modification and pathways of Southern Ocean deep waters in the Scotia Sea. Deep-Sea Res., 49A, 681-705.

- E. L. McDonagh, D. P. Stevens, K. J. Heywood, and R. J. Sanders, 2002b: On the export of Antarctic Bottom Water from the Weddell Sea. Deep-Sea Res., 49B, 4715-4742.

Nowlin, W. D., Jr., S. J. Worley, and T. Whitworth III, 1985: Methods for making point estimates of eddy heat flux as applied to the Antarctic Circumpolar Current. J. Geophys. Res., 90, 33053324.

Olbers, D., and J. Wenzel, 1989: Determining diffusivities from hydrographic data using inverse methods with application to the Circumpolar Current. Ocean Circulation Models: Combining Data with Dynamics, D. Anderson and J. Willebrand, Eds., Kluwer, $95-140$

_, V. Gouretski, G. Seiss, and J. Schroeter, 1992: Hydrographic Atlas of the Southern Ocean. Alfred Wegener Institut für Polarund Meeresforschung, 17 pp. and 82 plates.

Orsi, A. H., T. Whitworth III, and W. D. Nowlin Jr., 1995: On the meridional extent and fronts of the Antarctic Circumpolar Current. Deep-Sea Res., 42, 641-673.

, G. C. Johnson, and J. L. Bullister, 1999: Circulation, mixing 
and production of Antarctic Bottom Water. Progress in Oceanography, Vol. 43, Pergamon, 55-109.

Peterson, R. G., 1992: The boundary currents in the western Argentine Basin. Deep-Sea Res., 39A, 623-644.

Phillips, H. E., and S. R. Rintoul, 2000: Eddy variability and energetics from direct current measurements in the Antarctic Circumpolar Current south of Australia. J. Phys. Oceanogr., 30, 3050-3076.

Piola, A., and A. L. Gordon, 1989: Intermediate water in the southwestern South Atlantic. Deep-Sea Res., 36, 1-16.

Polzin, K. L., J. M. Toole, G. R. Ledwell, and R. W. Schmitt, 1997: Spatial variability of turbulent mixing in the abyssal ocean. Science, 276, 93-96.

Rintoul, S. R., 1991: South Atlantic interbasin exchange. J. Geophys. Res., 96, 2675-2692.

— C. W. Hughes, and D. Olbers, 2001: The Antarctic Circumpolar Current system. Ocean Circulation and Climate, G. Siedler, J. Church, and J. Gould, Eds., Academic Press, 271-302.

Rivas, A. L., 1994: Spatial variation of the annual cycle of temperature in the Patagonian shelf between $40^{\circ}$ and $50^{\circ}$ of south latitude. Cont. Shelf Res., 14, 1539-1554.

Roemmich, D., 1983: Optimal estimation of hydrographic station data and derived fields. J. Phys. Oceanogr., 13, 1544-1549.

Schodlok, M. P., H. H. Hellmer, and A. Beckmann, 2002: On the transport, variability and origin of dense water masses crossing the South Scotia Ridge. Deep-Sea Res., 49B, 4807-4825.

Sloyan, B. M., and S. R. Rintoul, 2000: Estimates of area-averaged diapycnal fluxes from basin-scale budgets. J. Phys. Oceanogr., 30, 2320-2341.
— and - 2001: The Southern Ocean limb of the global deep overturning circulation. J. Phys. Oceanogr., 31, 143-173.

Smith, W. H. F., and D. T. Sandwell, 1997: Global sea floor topography from satellite altimetry and ship depth soundings. Science, 277, $1956-1962$.

Speer, K., and E. Tziperman, 1992: Rates of water mass formation in the North Atlantic Ocean. J. Phys. Oceanogr., 22, 93-104.

- , S. R. Rintoul, and B. M. Sloyan, 2000: The diabatic Deacon cell. J. Phys. Oceanogr., 30, 3212-3222.

Stammer, D., 1998: On eddy characteristics, eddy transports, and mean flow properties. J. Phys. Oceanogr., 28, 727-739.

Sun, C., and D. R. Watts, 2001: A circumpolar gravest empirical mode for the Southern Ocean hydrography. J. Geophys. Res. 106, 2833-2855.

Talley, L. D., 1996: Antarctic Intermediate Water in the South Atlantic. The South Atlantic: Present and Past Circulation, G. Wefer et al., Eds., Springer-Verlag, 219-238.

Tandon, A., 2001: Water mass transformation due to mixed layer entrainment and mesoscale stirring: In series or parallel? From Stirring to Mixing in a Stratified Ocean: Proc. 'Aha Huliko'a Hawaiian Winter Workshop, Honolulu, HI, University of Hawaii at Manoa, 105-111.

Whitworth, T., III, W. D. Nowlin Jr., and S. J. Worley, 1982: The net transport of the Antarctic Circumpolar Current through Drake Passage. J. Phys. Oceanogr., 12, 960-971.

_ A. H. Orsi, R. A. Locarnini, and S. G. Smith, 1994: Weddell Sea shelf water in the Bransfield Strait and WeddellScotia Confluence. Deep-Sea Res., 41A, 629-641.

Wunsch, C., 1996: The Ocean Circulation Inverse Problem. Cambridge University Press, $442 \mathrm{pp}$ 